\title{
الإفادة هن القطع النسجية سابقه الإعداد في إثراء المشغولة الفنية
}

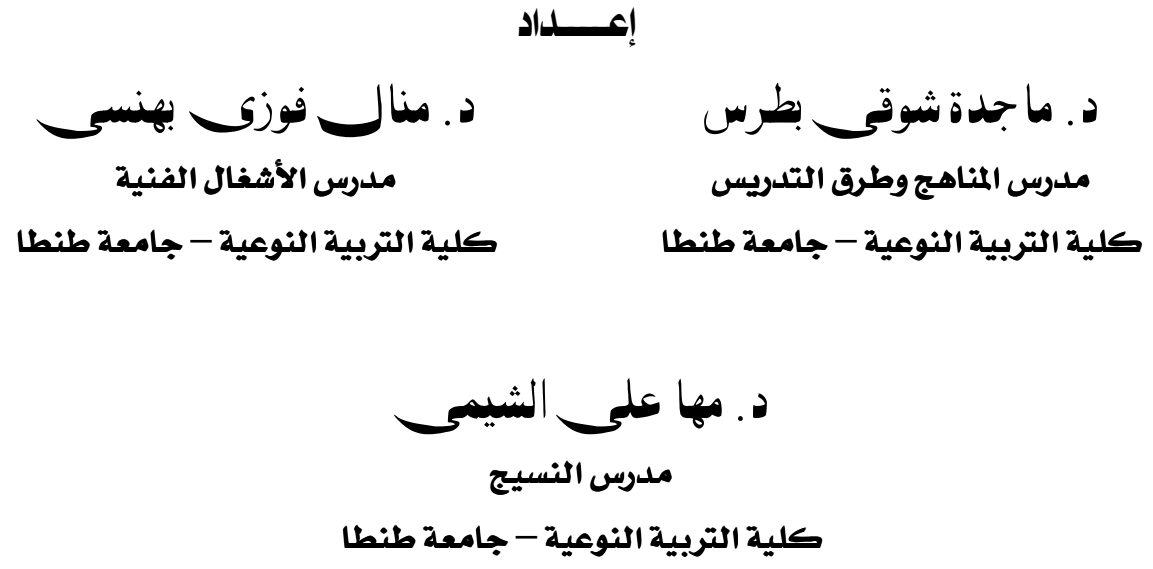




\section{الإفادة هن القطع النسجية سابقه الإعداد في إثراء المشغولة الفنية المالية}

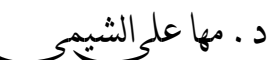

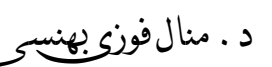

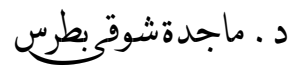

هقدهة:

يعد مجال الأشغال الفنية من المجالات الهامة في مجال التربية الفنية ويتطلب هذا المجال المال

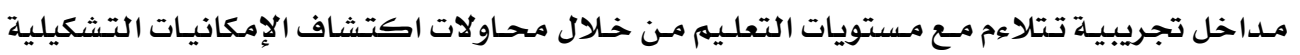

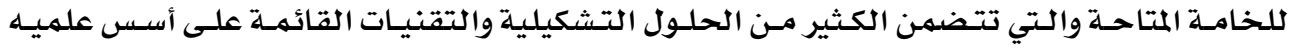

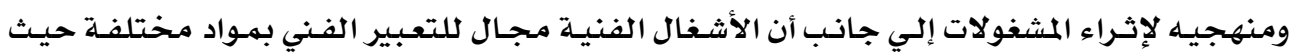

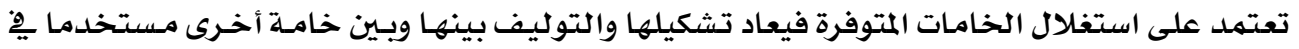

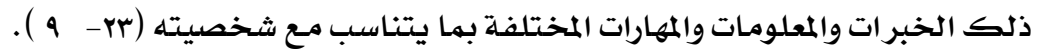

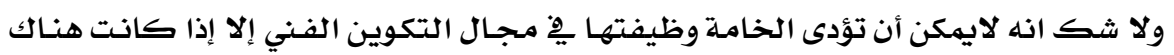

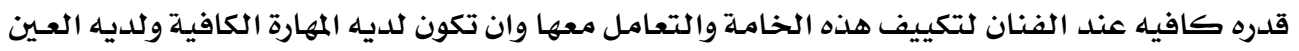

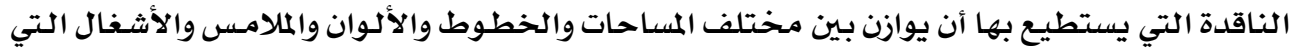

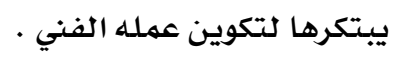

وحيث أن الأشغال الفنية هي المجال الفني الذي يتناول التعبير الفني بمختلف الخامات لذات لذا

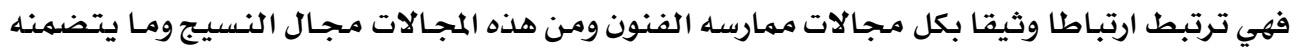

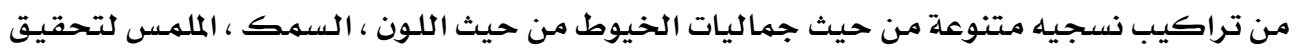
قيما فنيه عاليه من خلال تعاشق الخيوط والتوليف بينها وبين خامات أخرى .

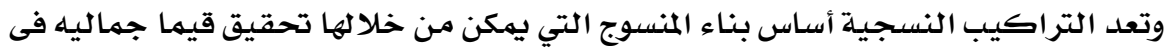

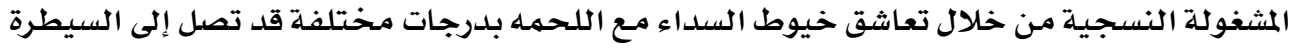

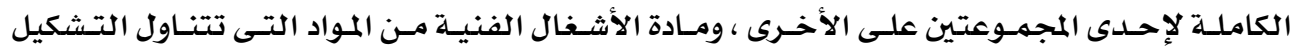

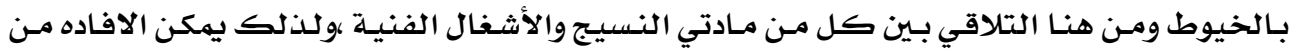

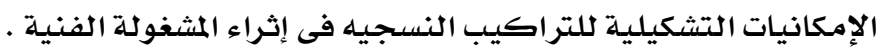

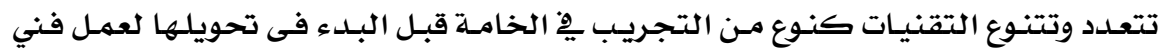

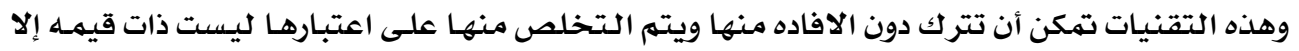

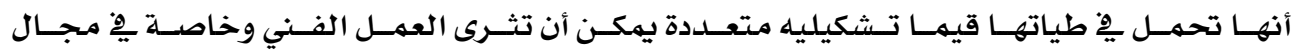
الأشغال الفنية .

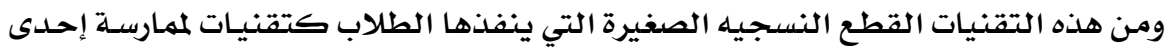

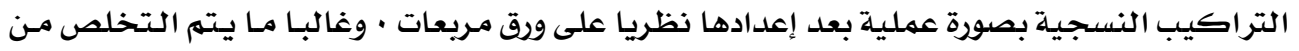

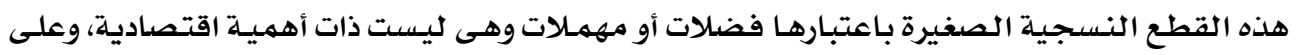




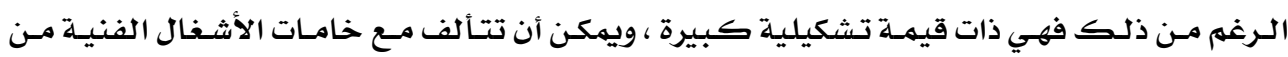
خيوط متتنوعة ذات قيما لونية وملمسية ومن هذا التلاقي تتحلدد مشكلة البحث في السؤال التالى الى

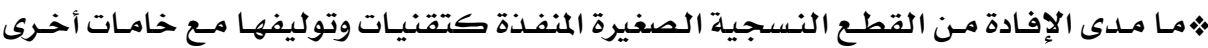
لإثراء المثغولات الفنية.

ترجـع أهميلة هذا البحث إلى : • تقديم مدخل جديد لتدريس الأشغال الفنية

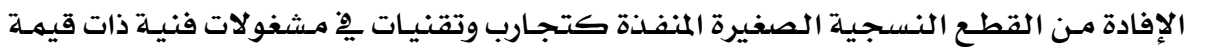
جمالية وتربوية. توليف الخامات يساعد على إيجاد قيما تشكيلية تثرى المشغولة الفنية

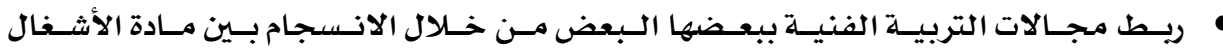

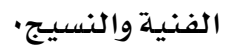
أهداف البحث

$$
\text { يهدف البححث الحالى الى : }
$$

الإفـادة مـن الإمكانيـات التشكيلية للقطع النسجية الصغيرة يِّ إثراء المشغولة الفنيـة وكذا

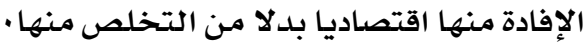

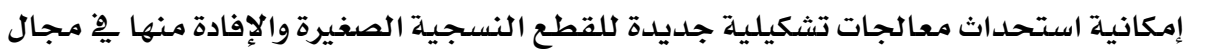
الأشغال الفنية.

•التوليف بين التراكيب النسجية وخامـات الأشغال الفنية كأسلوب مستحدث لتدريس مجال الأثغال الفنية.

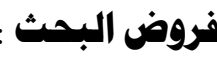

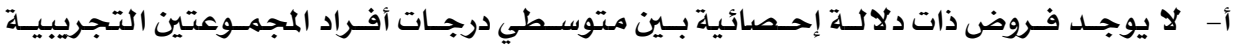

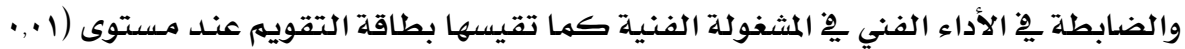
) فى الأداء القبلي

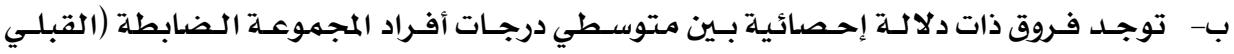

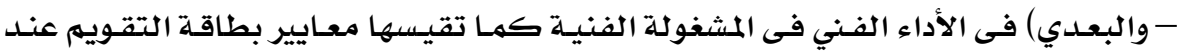
مستوى (1...• ) لصالح القياسات البعدية. ج- توجد فروق ذات دلالة إحصائية بين متتوسطي درجـات أفراد المجموعـة التجريبيـة في القياس

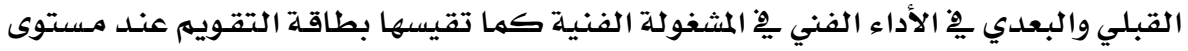

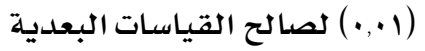


د- توجد فروق ذات دلالة إحصائية بين متوسطي درجات أفراد المجموعتين التجريبيـة والضابطة

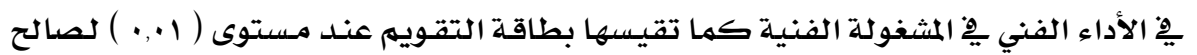

القياسات البعدية.

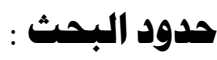

الحدود الزمنية:

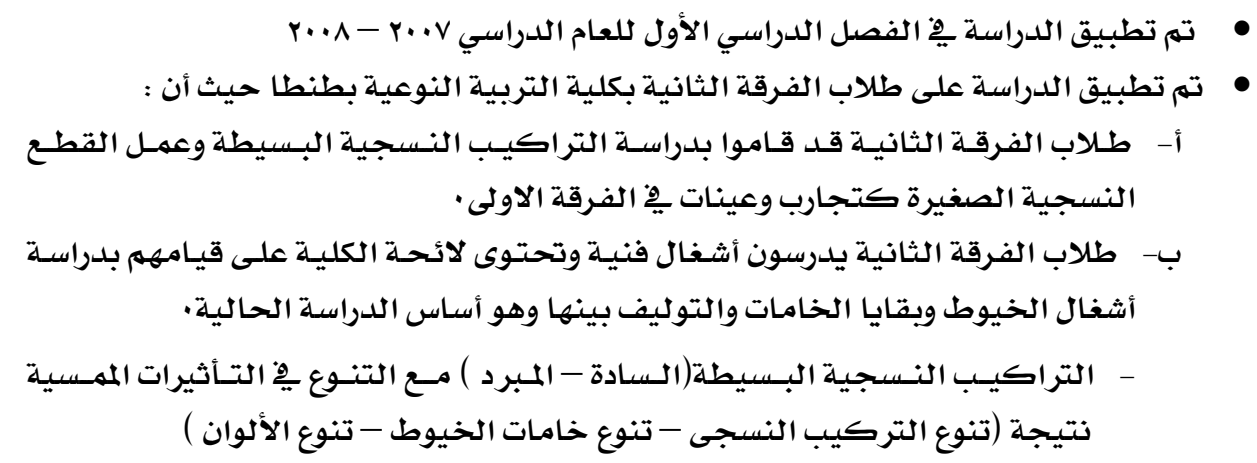

- - تنفيذ معلقات يِّ مجال الأشغال الفنية.

- اقتصر تقدير الأداء الفني ببطاقة تقويم الأداء الفني ( من إعداد الباحثة )

هنهج البمث

يتيح البحث المنهج التجريبي وتسير تجربه البحث وفقا للتصميم التالي

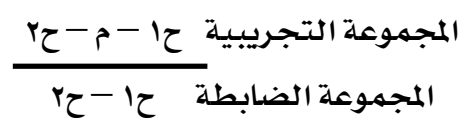

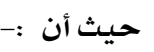

حا هو القياس القبلي pretest للأداء الفني ِِِ المثغولة الفنية م تلقاءات التدريس

حr هو القياس البعدي post-rest للأداء الفني يو المشغولة الفنية

عدد أفراد العينه • ج طالب وطالبه قسمت إلي مجموعتين كل مجموعه .r طالب وطالبه

\section{منطالقات التجريب}

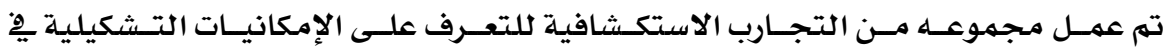

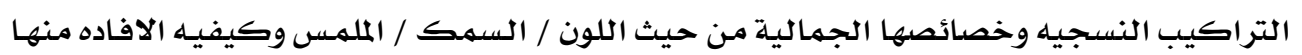

مـع خامات الأشغال الفنية من أقمشة وخيوط وجلود وخامات متنوعة . 


$$
\begin{aligned}
& \text { يقوم التجريب على مجمموعه من المتغيرات على احد الثوابت } \\
& \text { • الثشوابت : المشغولة الفنية }
\end{aligned}
$$

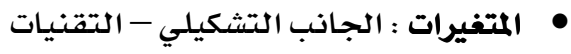

\section{أدوات التجربة}

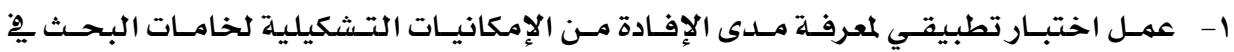

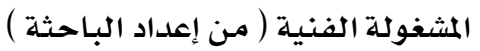

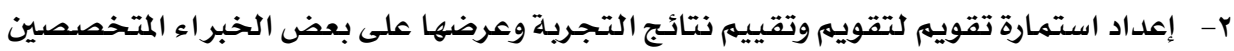

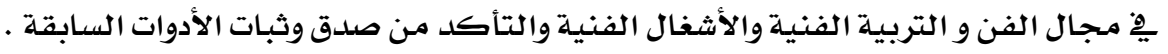

\section{الخاهات المستخدهة}

$$
\begin{aligned}
& \text { ا- القطع النسجية الصغيرة المنفذة كتقنيات وتجارب } \\
& \text { r- بقايا الأقمشة مختلفة الملمس واللون } \\
& \text { r- ب - بعض الإكسسوارات } \\
& \text { ع- مجموعه من الخيوط متنوعة اللون والسهك }
\end{aligned}
$$

\section{الإسطات والإطار النظري من الخيوي}

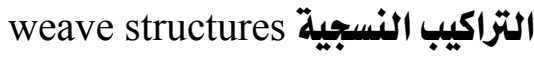

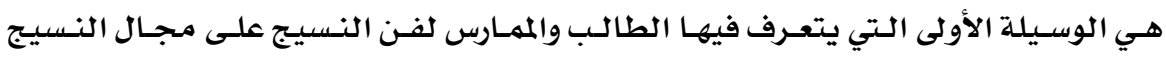

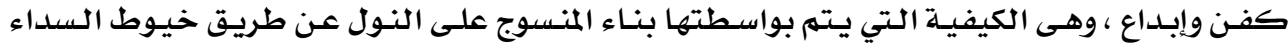

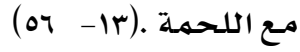

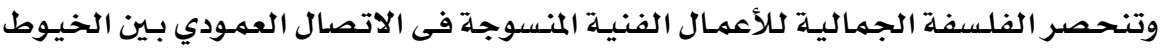

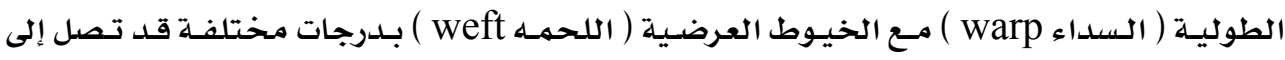
السيطرة الكاملة لإحدى المجموعتين على الأخرى فتظهر خيوط السداء مسيطرة على سطح القماث

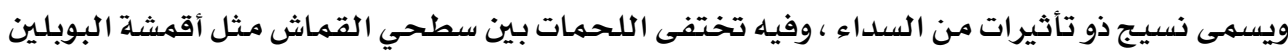
والجبردين وقد يحدث العكس فيصبح التركيب البنائى ذو تأثيرات من اللحمـه وفيه تسيطر اللحئ الحمـات

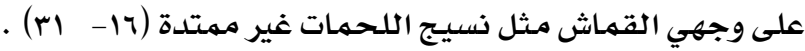
ومن التراكيب النسجيه البسيطة النسيج السـادة والمبرد ورغم بساطه الشكل والأداء إلا انـه

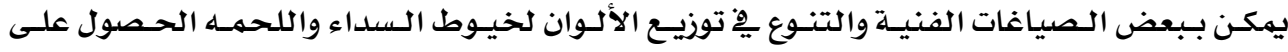

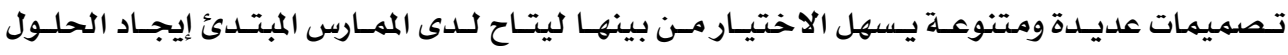

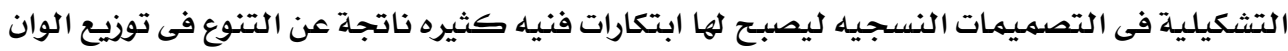
السداء واللحمـه مـع فرص تنوع التصميم والخامـة . 
ويقوم الطالب الممارس المبتدئ لفن النسيج بدراسـة هذه التراكيب النسسجيه البسيطة نظريا أولا على ورق المربعات ثم يطبقها عمليا على مسـاحات صغيره كتجـارب وتقنيـات ثم تعامل على أنها

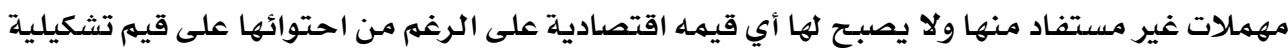

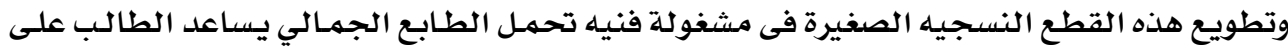

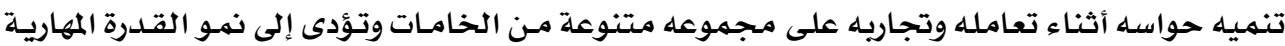

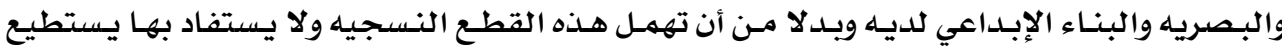
العقل الابتكارى أن ينظر إليها ويـصوغها بحيث يحولها إلى ابتكارات فنيـه ذات علاقات جماليـاته مـثيره

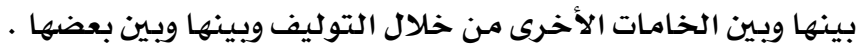

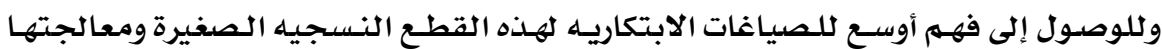

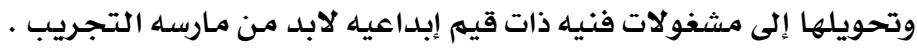

فالتجريب أسلوب ِِِ الأداء الفـني يبحث عن متعلقـات تشكيلية جديدة وعن حلـول متعددة لتقديم رؤى فنيـ جديدة .

والتجريب يصاحب كل عقليـه مفكره ابتكاريـه تبحـث عن مضمون جلديد حتى فى الرؤيـة المألوفة فغاية التجريب هى السعي والتدريب على ممارسه الفكر الابتكارى.

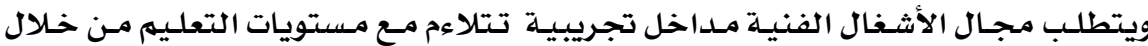
اكتشاف صياغات فنية جديدة تتضمن العديـد مـن الحلـول التشكيلية والتقنيـات ، فاختيـار الخامـات وتوليفها وتشغيلها هام جدا بالنسبة لهذه الأعمال (q- بعاه ). والتجريب فى هذه الدراسة يتم على محورين:

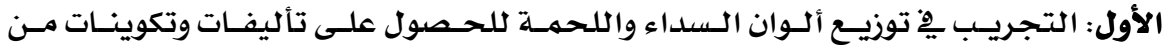

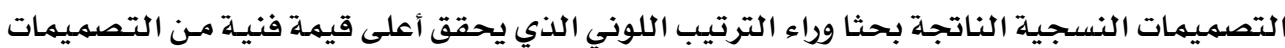

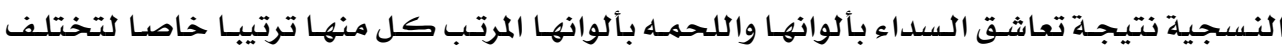

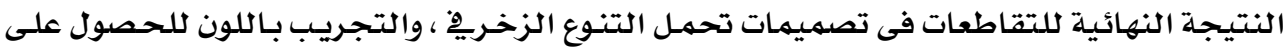
بعض التصميمات الزخرفية للنسيج السادة والمبرد قد ينتج تصميمات واسعة النطاق يصعب حصرها . الثاني : التجريب يِّ تآلف هذه القطع النسجية وفق خاماتها وألوانهـا مـع الخامـات الأخرى

$$
\text { فى توزيـع لونى مدروس. }
$$

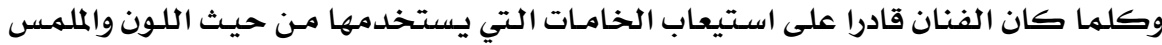

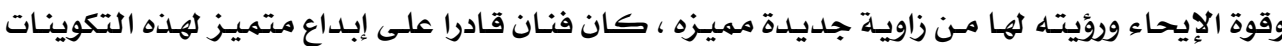

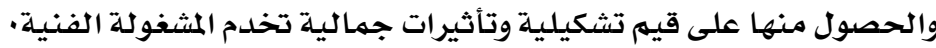
الثوليف :

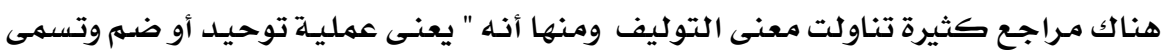

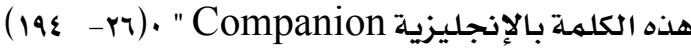




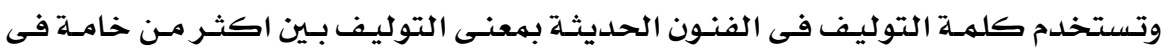

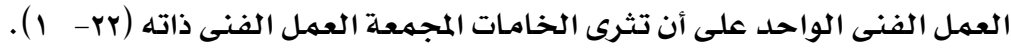

وفى المعاجم تستخدم كلمهة Collage على انه نوع من الفن التجريدي الذي تستخدلدم فيـا

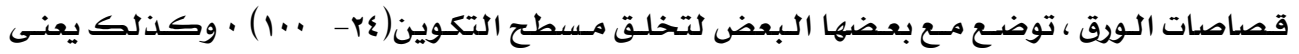

استغلال خامـات مختلفة مـن قصاصات ونفايات ، مـن وجهة نظر القيه التشكيلية ( جr- 1).

والتوليف فى الأشغال الفنية يعنى التزاوج والتوافق والتوحيد والضهم بـين اكثر مـن خامـة

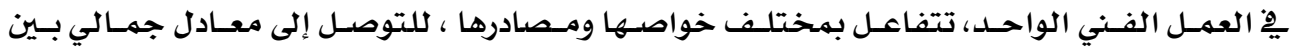

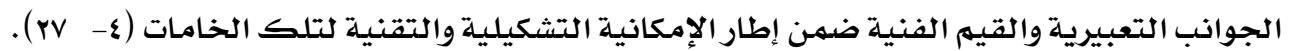
والمقـصود بـالتوليف عمليـا كمـا تشير فاطمسة المحهـودى إلى انـه " عمليـة المواءمسة حسين

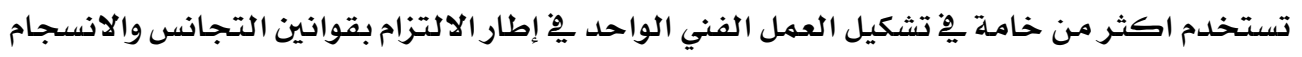

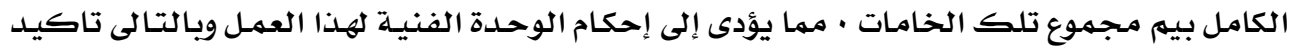

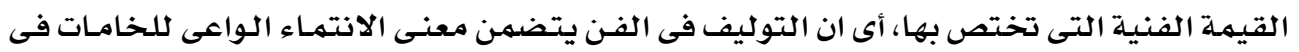

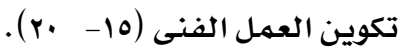

ولا يعنـى التوليـف قيـام الفنـان بتجميـع أى خـامـات مـع بعـضها مهمهـا تباينـت خصائـصها

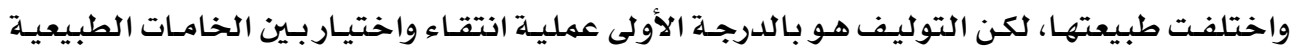

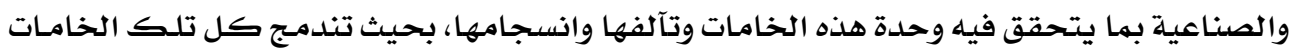

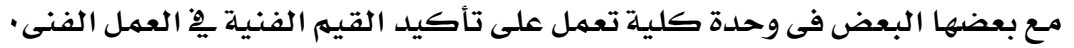

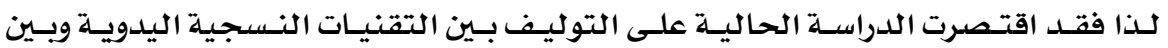
الأقمشة والخيوط والجلود وبعض المكملات.

وتؤكد عواطف المرصفى على تناسب الخامـات مـع بعضها البعض فتعـرف التوليف على انه

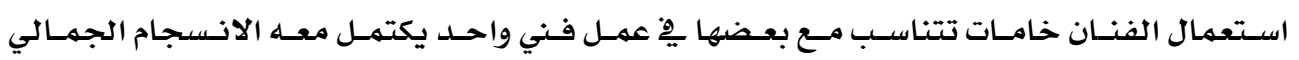

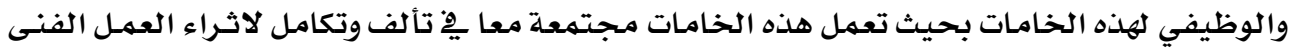

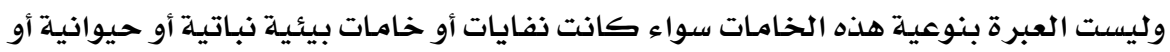

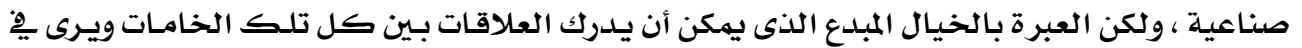

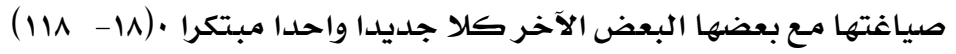
والتوليف قد يكون بـين التراكيب النسجية ذاتها وبـين الخامـات النسجية المستخدمـة فيها

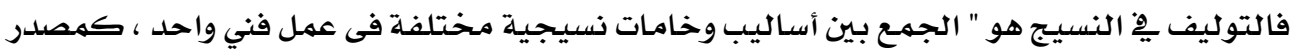

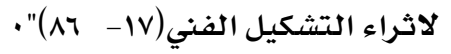

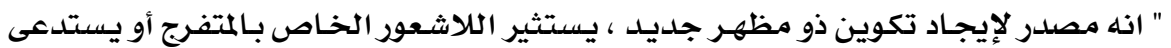

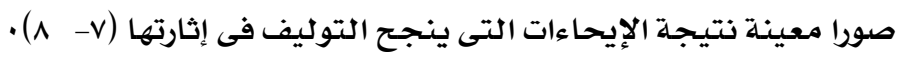




\section{أنواع الخيوط :}

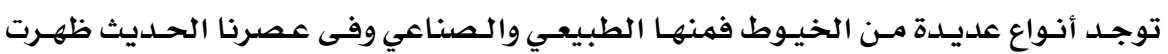

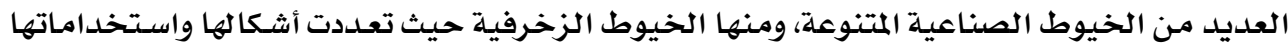

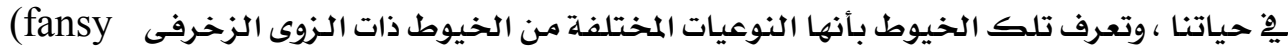

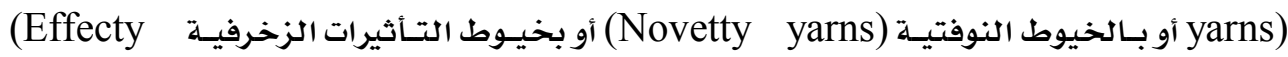
yarns)

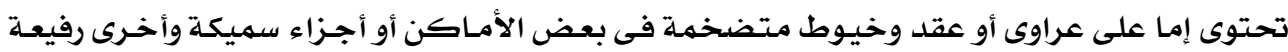

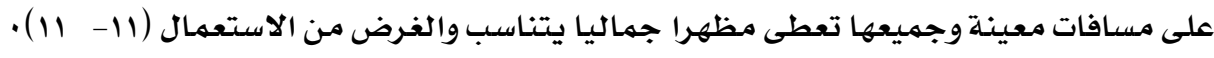

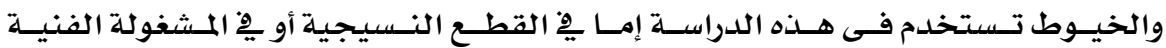
بتشكيلات متتنوعة. : الملامس

هو طبيعـة سطح العهـل الفنسى التى تميز مظهره أو هيئتسه والتى تحـرك مشـاعر وأحاسـيس

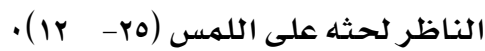

فالملمس تعبير يدل على الخصائص السطحية للمواد ، وهذه خصائص نتعرف عليها للوهلة

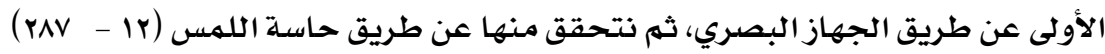
وتنقسم الملامس الى نوعين أساسيين:

: visual texture الملمس المرئى

ويعـرف بـالملمس ذو البعـدين حيـث يـتم إدراكـه بالبـصر دون اللهـس فهـو ينتقـل تأثيره عـن طريق العين ويحسـه العقل. الملمسس الحقيقـي Tactile texture وهـو ذو الثلاثــة أبعـاد ويـــرك عـن طريـق حاسـتي اللهـس والبصر (1)

وسواء كان الملمس مرئيـا أو حقيقيا فان أبرز خصائصده أن يثير لـدينا حساسـة اللمس ونحسن

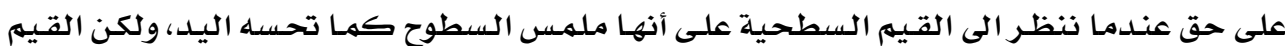

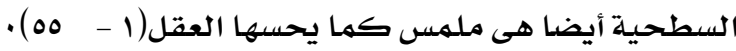

ويـرى ايهـاب بسمارك أن ملمس السطح هـو تلـك الأنساق التى تتخـذها مظـاهر السطوح

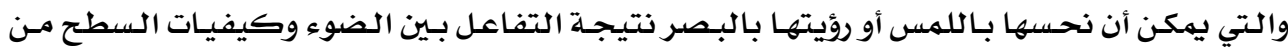

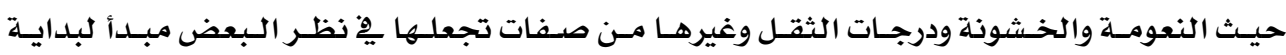

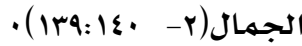

وقد تصنف ملامس السطوح من حيث الدرجة الى ملامس ناعمـة وخشنـة والملامس الخشنـة

إما منتظمهة أو غير منتظمهة

منتظمة : تنتج عن تكرار وحلدة معينة تكرارا منتظما وبشكل مستمر فى اتجاهات متبـاينة. 
غير منتظمة: لا تعتمد ٌِِ تشكيلها على تكراروحسدة معينـة بـل مـن توظيف وحسدة أو اكثر ِِّ إحـداث

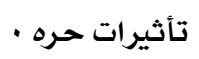

وقد تصنف الملامس من حيث النوع إما حقيقية ندركها عن طريق اللهس وهى طبيعيـة او

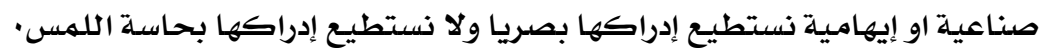

\section{أوجه الاختلاف بين ملمس وآخر:}

1) مدى انعكاس Reflection الضوء أو امتصاصده Absorption إذا سقط على مواد أو خامـات

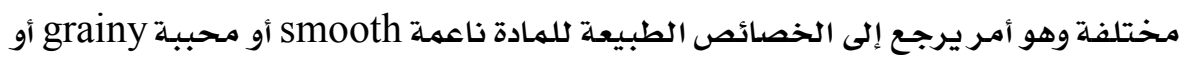
لامعحة

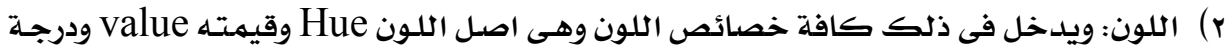

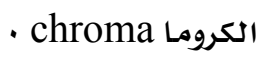

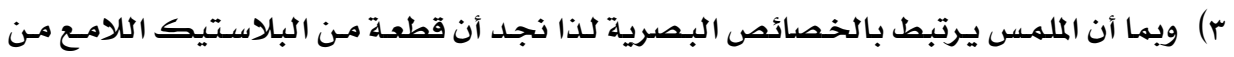

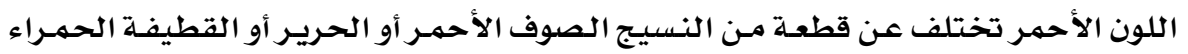

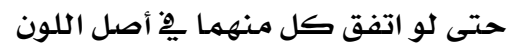

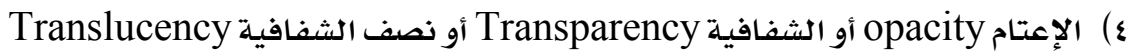

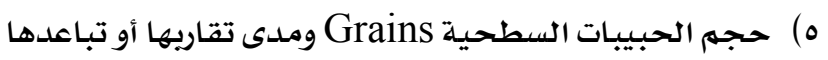

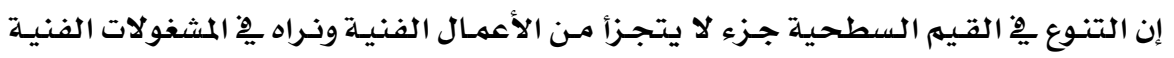

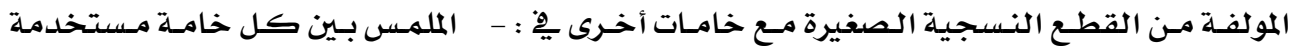

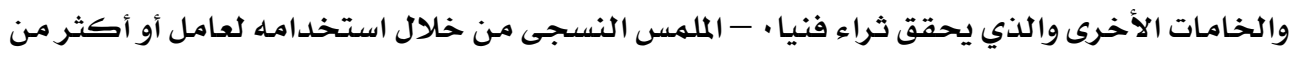

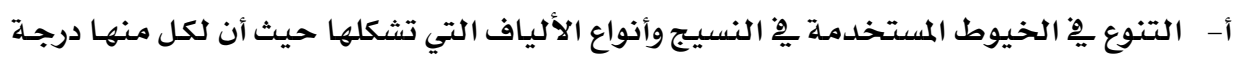

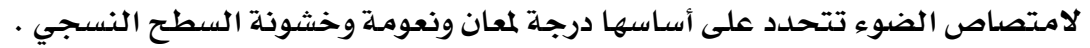

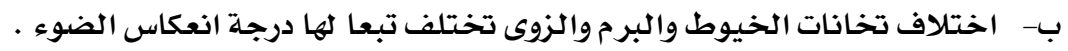

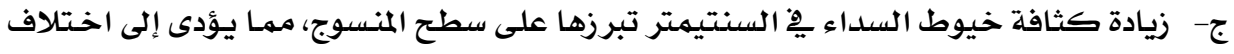
نسبة ظهور اللحمات والعكس صحيح عند ازدياد كثافة خيوط السداء .

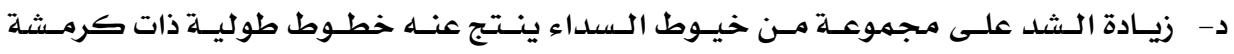
وأخرى ملسـاء.

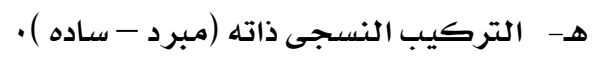

الإمكانيات التشكيلية للخامة التريب النشجات

أشـار مـرقص فـارس (·r - - با ) إلى الإمكانيـات التشكيلية بأنها القـدرات الفنيـة والمعطيـات

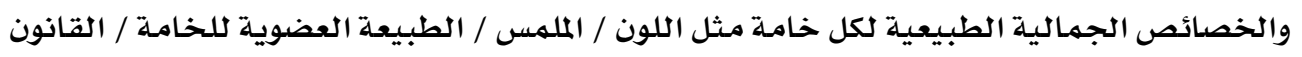
البنائى الذى يحكم والذى يؤثر فى الصياغات التشكيلية والتعبيرية للخامة من خلالال أسس التصميهم

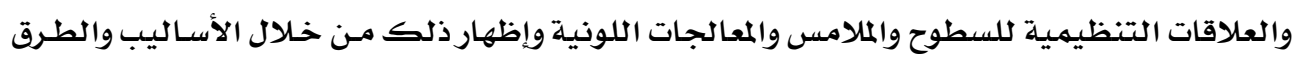


هنـاك كـثير مـن الدراسـات التى أشـارت إلى أهميـة التوليـف بـين خامـات البحث فـى مجــال

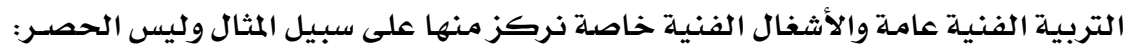

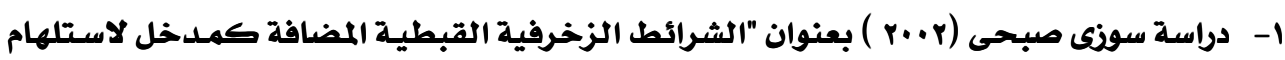

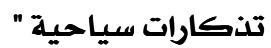

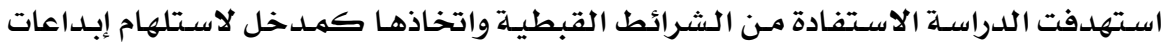

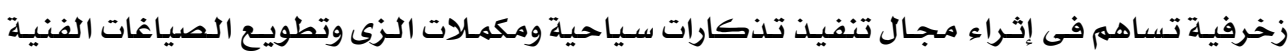

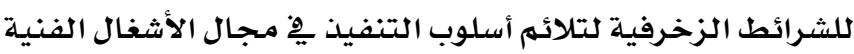
r- دراسة نبيل السيد (IqVI) بعنوان " اثر توليف الخامات النسجية ـِ التعبير الفـني عند تلاميذ

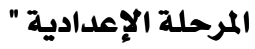

استهدفت هذه الدراسة الاستفادة من الخواص الطبيعية للخامـات النسجية يف تحقيق قيم

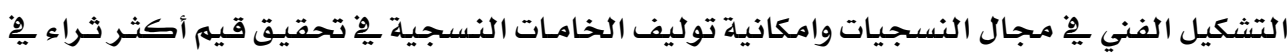

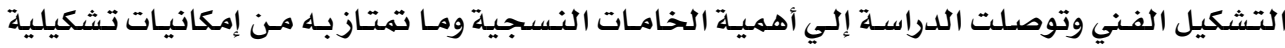
وقيم جماليـة.

r- دراسة محمد هانى فخري (194Y) بعنوان "التوليف بالخامات النسجية كمصدر لاثراء التشكيل الفني " درا

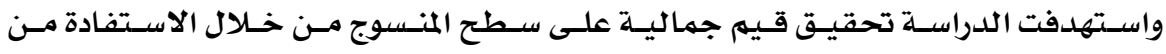

الخواص الطبيعيلة والجمالية للخامات النسجية وتوصلت إلى أن لكل خامـة إمكانيات تشكيلية خلية خاصسة

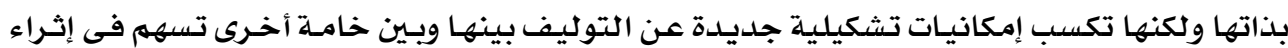

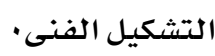

ع- دراسة سحر الهادي مصطفى (1999) بعنوان "الامكانات التشكيلية لبقايا الأقمشة والإفادة منها

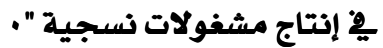

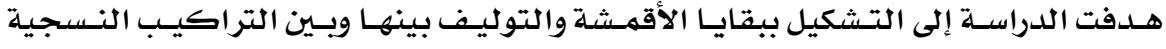

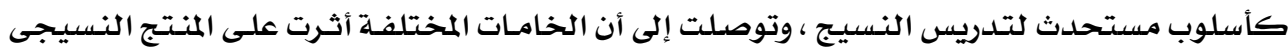

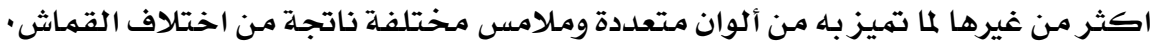

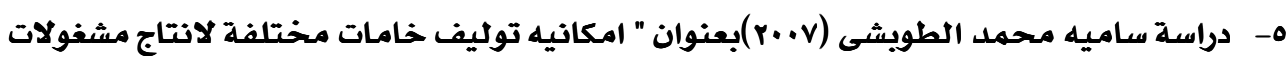

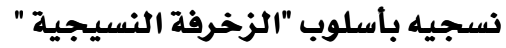

استهدفت الدراسـة إنتاج مشغولات نسجيه متنوعة تحقق القيم الجماليـة والنفعيـة المطلوبـة

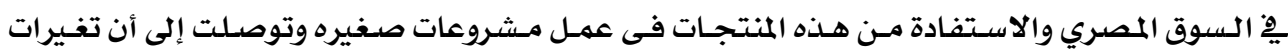

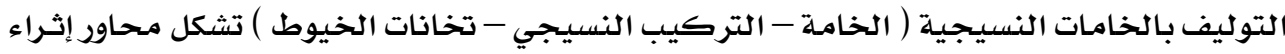

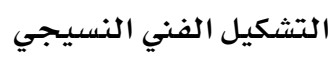


قامت البـاحثة بإعداد وبناء برنـامـج تريـوى لإثراء المشغولة الفنيـة لدى طلاب شعبـة التربيـة الفنية بكلية التربية النوعية

وقد تم فيـ مراعاة الأسس والخطوات العلميلة والتربوية عند بناء البر نامج ويهكن تحديـدها فيما يلى :

أولا : تحديد أهداف البرنامج :

قامت الباحثة بإعداد أهداف البر نامج العامـة والسلوكية والتى اشتملت على ثلاثـة أهـاف

عامـة ترجم كل منها إلى مجموعة مـن الأهداف السلوكية وهى :

1) تنميلة القدرة على إدراك القيم الفنية التشكيلية فى التصميهم وارتباطها بتقنيات التشكيل

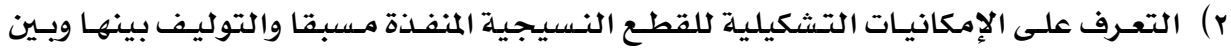

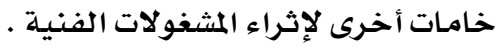

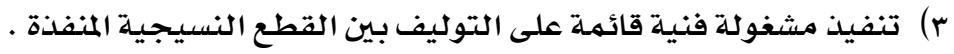

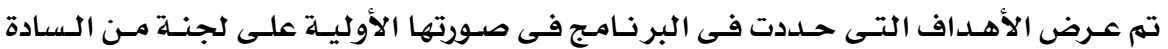

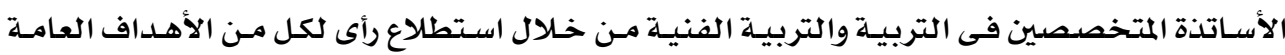

والسلوكية وتم مـراعاة آرائهم وتتفيذها حتى أصبحت الأهداف فى صورتها النها النهائية .

ثانيا : تنظيم وصياغة محتوى البرنامج :

لتحقيق الأهداف تم تقسيم محتوى البر نامـج إلى جانبين :

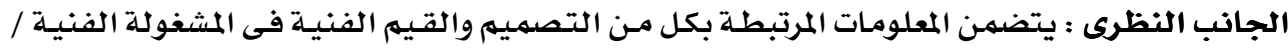

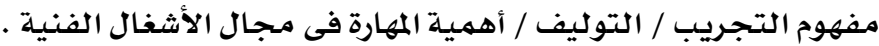

الجانب التطبيقى : يشتمل على كيفيـة الإفـادة مـن الإمكانيات التشكيلية لخامـة البحث مـن خـالال

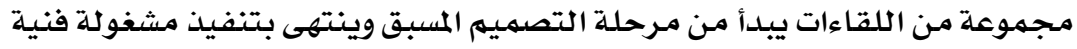

اللقاء الأول : يهدف إلى الإفادة من الإمكانيات التشكيلية من القطع النسجية المنفذة ويتعرف الطالب

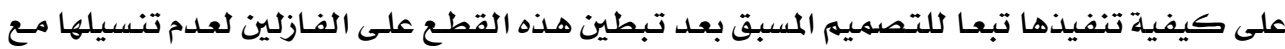

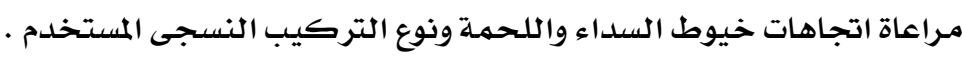
اللقاء الثانى : يهدف إلى التعرف على الإمكانيـات التشكيلية لبقايـا الأقمشة والخيـوط بأنواعها مـن

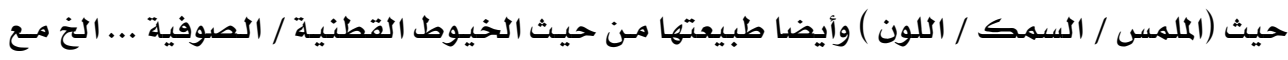

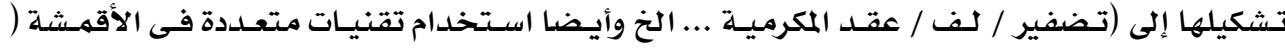

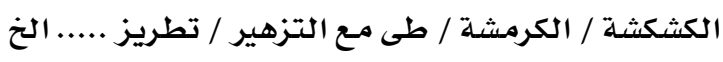

ويعرض عليهم مجموعة من التقنيات المنفذة من قبل الباحثة بأسـاليب تشكيلية مختلفـة ( 
اللقاء الثالث : يهلدف إلى تنفيذ معلقة قائمسة على توليف القطـع النسيجيـة المنفـذة مسبقا مـع بقايا

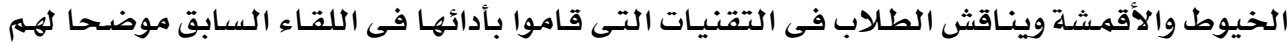

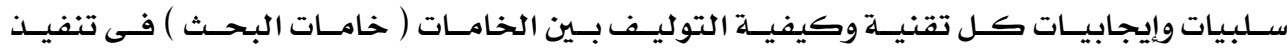

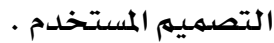
اللقاء الرابع : يناقث الطلاب فى التجارب ( التقنيات ) التى قاموا بتنفيذها فى اللقاء السـابق ومدىى مـلاءمتها لإجـراء التصميهم وتوزيـع كل خامـة بتقنياتها مـع كل جزء من أجزاء التصميهم . اللقاء الخامس : استكمالا للقاء السـابق فى تشكيل المشغولة الفنية ومعرفة نواحي القوة والضعف فى

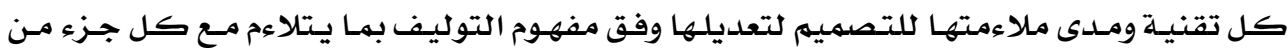

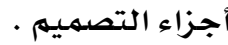

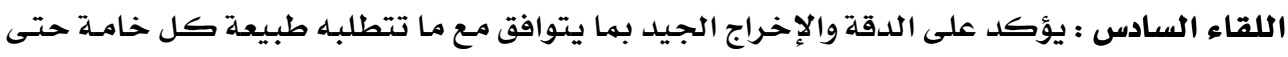

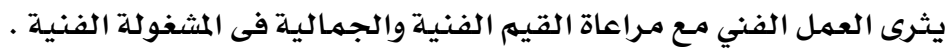
ثالثا : اختيار الأنشطة والوسائل التعليمية وتتضمن : 1) بعض الصور والنماذج التي تتضح فيها القيهم الفنية فى التصميهم المسبق لأي عمل فني ناجـح .

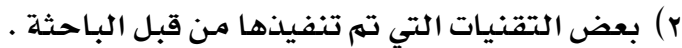

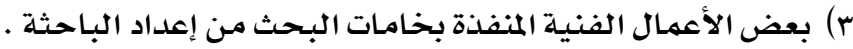
وتتضمن الأنشطة :

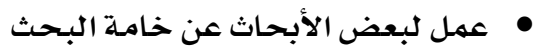

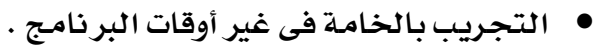

رابعا : طرق التدريس

إن كل خطة يضعها المعله لابد لها من طريقة تدريس تتناسب معها لتحقيقها وعلى المعلىم

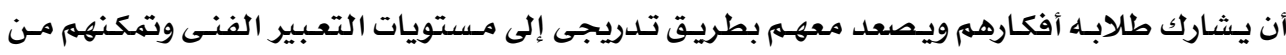

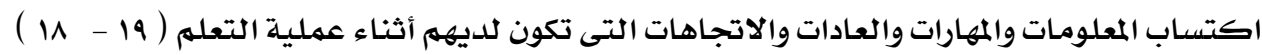

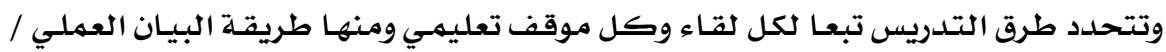

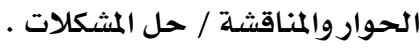

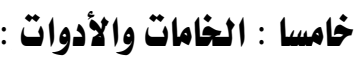
تنقسه الخخامات تبعا لكل لقاء :

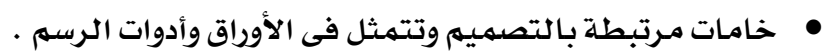

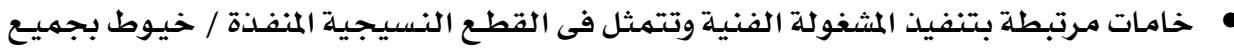

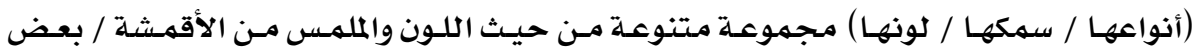

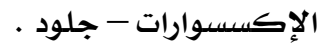




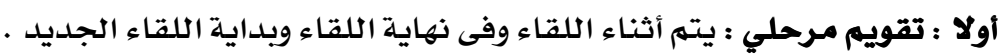

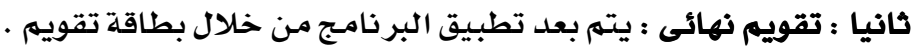

سابعا : التحكيم على صلاحية البرنامج :

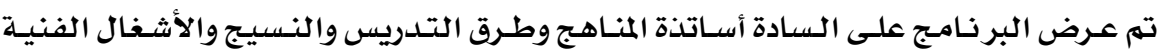

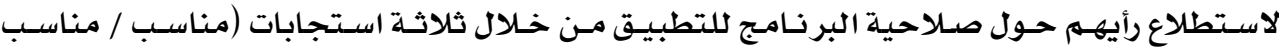

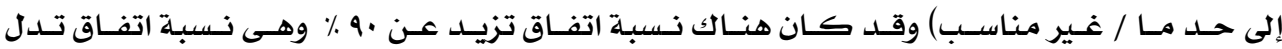

أولا : خطوات إعداد بطاقة تقويم المشفولة الفنية :

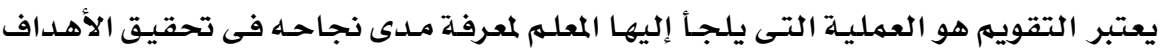

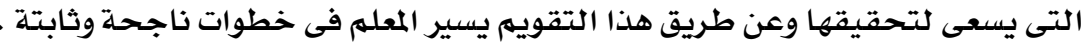

وللتقويم أهداف وهى معرفة وفهم المتعله لما درسه من حقائق ومعلومات ومعرفة نوع المهارات

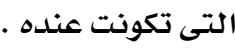

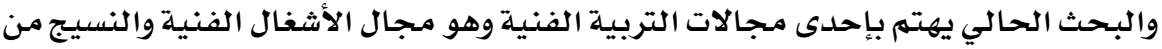

خلال الإفادة من بعض قطع النسيج المنفذة ( سابقة الإعداد ) والإفادة منها في إثراء المشغولة الفنية . ولذلك تقوم الباحثة بإعداد بطاقات لتقويم المشغولة الفنية للطلاب اتبعت فى تصميمها

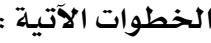

$$
\begin{aligned}
& \text { تم اختبار (ه) معايير للحكم على مدى ثراء المشغولة الفنية وهى : }
\end{aligned}
$$

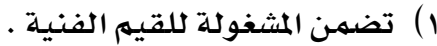

$$
\begin{aligned}
& \text { r r الحقيق التآلف بين القطع النسيجية المسبقة والخامات المؤلفة في تشكيل المثغولة . }
\end{aligned}
$$

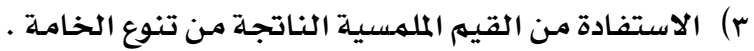

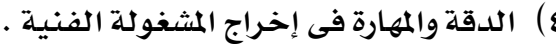

$$
\begin{aligned}
& \text { ه) استحداث صياغات تشكيلية نتيجة استخدام خامات وتقنيات متنوعة . }
\end{aligned}
$$

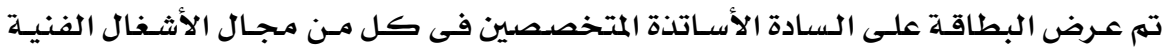

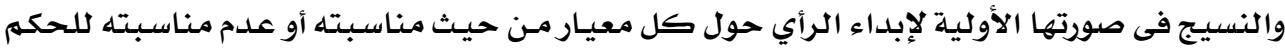

على المشغولة الفنية وعمل التعديلات طبقا لاتفاق معظم آرائهم . طريقة تقدير اللدرجات : ماتل

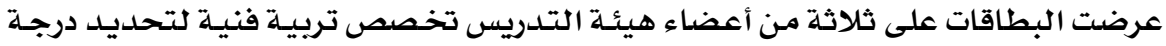

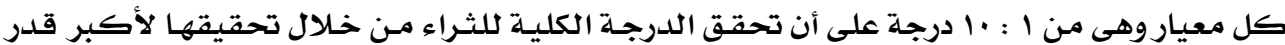


من معايير التقويهم وكلما اقتربت الدرجـة من النهاية العظمى ( .0 ) درجة دل ذلك على ثراء المشغولة

\section{صلق البطاقة :}

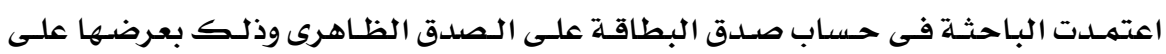

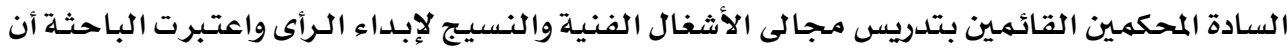

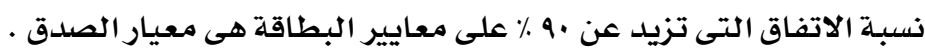

\section{ثانيا : خطوات إعلاد الاختبار التطبيقى :}

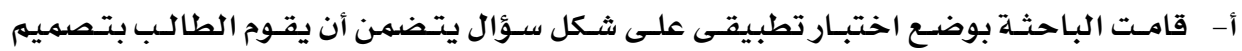

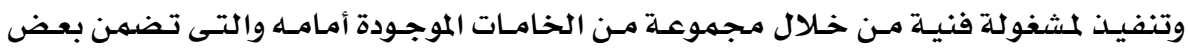

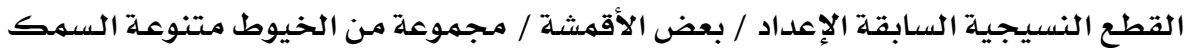

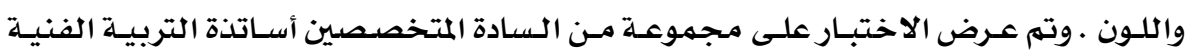

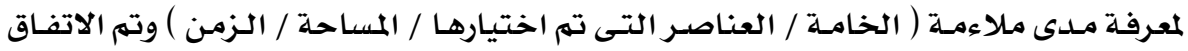

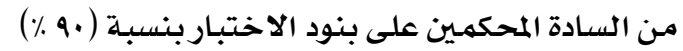

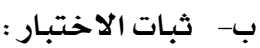

تم تحديد ثبات الاختبار بتطبيقه على عينـة من طلاب الفرقة الثانية شعبـة تربية فنيـة ، ثم الما

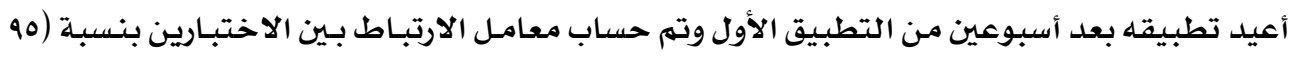

\% ) وهى نسبـة تجعل الاختبار ثابتا .

ثالثا : التجربة الاستطلاعية :

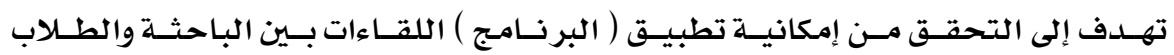

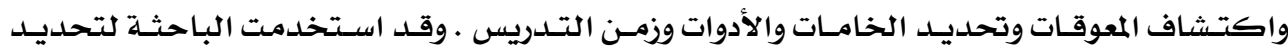

الزمن عن تطبيق الاختبـار التطبيقى المعادلة الآتية

الزمن الذى يستغرقه أسرع الطلاب + الزمن الذي يستغرقه أبطأ الطلاب

$$
\text { واستطاعت تحدد الزمن بالمعادلة الآتية : }
$$

\section{عينة الدراسة :}

تم اختيار عينـة البحثث مـن طلاب الفرقـة الثانيـة تربيـة فنيـة بكليـة التربيـة النوعيـة بطنطا

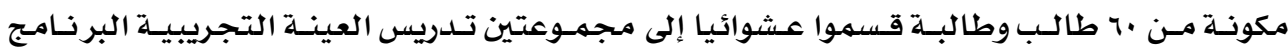

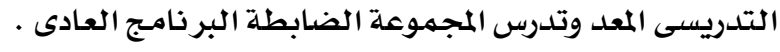




\section{نتائج الأداء القبلى :}

للتأكد من تجانس مجمهوعتى البحث فى الأداء الفنى فى الأثـغال الفنيـة قامـت

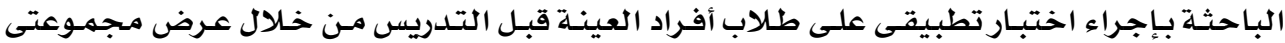

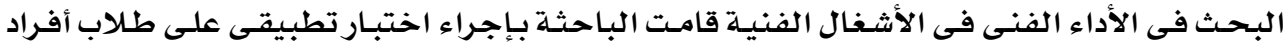

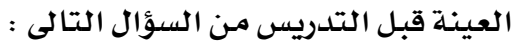

( أمامك مجموعة من الخامات المتنوعة والأدوات المختلفة وعليك تصميهم وتنفيذ مشغولة

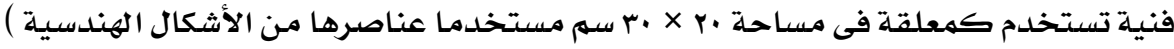

وقد استخدمت الباحثة المعادلة الآتية فى حساب الفروق بين المتوسطات حيث أن :

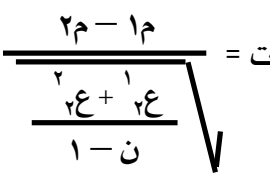

حيث يـل الرمز ما على المتوسط الحسابى للهجمهوعة الأولى حيث يدل الرمـز مب على المتوسط الحسابى للمجموعة الثانية حيث يدل الرمززن على عدد أفراد إحدى المجموعتين لتساوى كل منهم حيث يدل الرمزعزا على تباين المجموعة الأولى

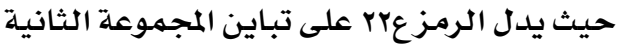

تم حساب فروق المتوسطات بين المجموعة التجريبية والضابطة فى التطبيق القبلى والجـدول التـالى يوضـح المتوسـطات الحسـابية والانحـراف المعيـارى وقيمـة ت لكل مـن درجـات

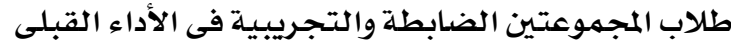




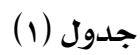

دلالة الفروق بين متوسطات القياسات القبلية للأداء الفنى للمشغولة الفنية لدى المجموعتين التجريبية والضابطة

جلدول رقم

\begin{tabular}{|c|c|c|c|c|c|c|c|}
\hline \multirow{2}{*}{ مستوى } & \multirow{2}{*}{ 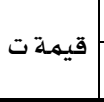 } & \multicolumn{2}{|c|}{ الانحراف المعيارى } & \multicolumn{2}{|c|}{ المتوسط الحسابى } & \multirow{2}{*}{ معايير التقويم } & \multirow{2}{*}{ s } \\
\hline & & ضابطة & تجريبية & ضابطة & تجريبية & & \\
\hline 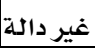 & 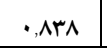 & $\cdot, \mathrm{VV} T \mathrm{I}$ & $\cdot, \vee \vee \leqslant 9$ & $1,174 \mathrm{~V}$ & r.rrr & |تضمن المشغولة للقيم الفنية & 1 \\
\hline 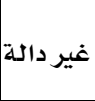 & $\cdot, 799$ & $\cdot$, vir & $\cdot \operatorname{vr} \leqslant q$ & $1,9 \ldots$ & r.rrTr & 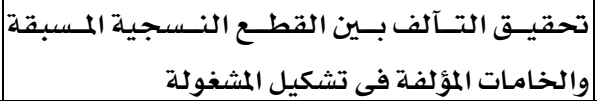 & $r$ \\
\hline 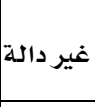 & -orr & $\cdot, V \leqslant Y \wedge$ & $\cdot$, vIr & $r, \cdots$ & $1,9 \ldots$ & 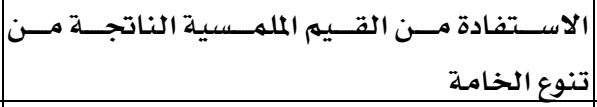 & $r$ \\
\hline 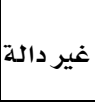 & $-1, Y 71$ & $\cdot, V \mid \leqslant \varepsilon$ & $\cdot, \vee \backslash \wedge \varepsilon$ & $r, r \ldots$ & $1,977 \mathrm{~V}$ & 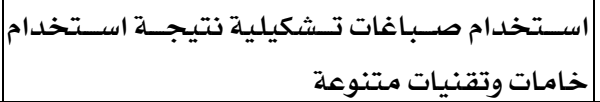 & $\varepsilon$ \\
\hline 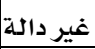 & -rr. & $\cdot, \Lambda Y V V$ & $\cdot, \vee \wedge \vee \wedge$ & Y,. TTV & $r, \cdots$ & الدقة والمهارة فى إخراج المشغولة الفنية & 0 \\
\hline 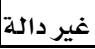 & $-\varepsilon १ \uparrow$ & I,VYrV & $1,9 \leqslant 9 \leqslant$ & $1 \cdot 17 \mathrm{TV}$ & 9,9rrr & |الدرجة الكلية (الثراء) & 7 \\
\hline
\end{tabular}

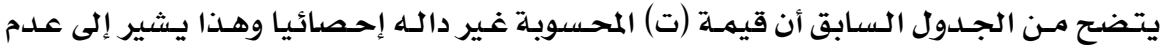

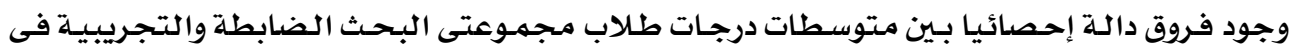

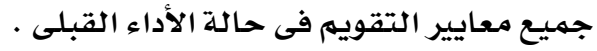
وبذلك يعطى دلالة مباشرة على تكافؤ المجموعتين قبل تدريس البرنامج ·

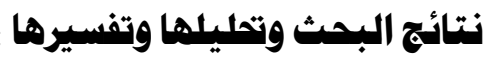

$$
\text { فيما يلى عرض للنتائج إلى توصلت إليها الباحثة . }
$$

أولا : تم المعالجة الإحصائية للفرض رقم (1) الأداء القبلى سابقا .

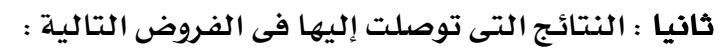

$$
\text { لاختبار صحة الفرض الثانى الذى ينص على : }
$$

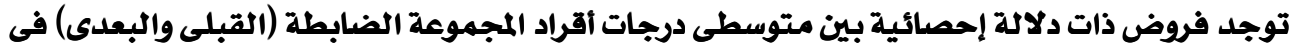

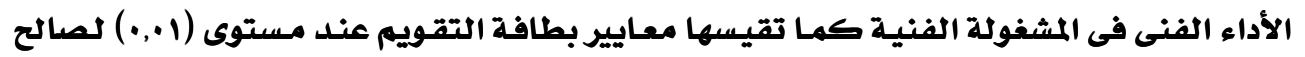




$$
\text { جدول r }
$$

المتوسطات الحسابية والانحرافات المعيارية وقيمهة (ت) ومستتوى الدلالة لطلاب المجهموعة الضابطة

مِيْ الأداء (القبلي - البعدي)

\begin{tabular}{|c|c|c|c|c|c|c|c|}
\hline \multirow{2}{*}{ 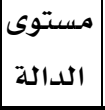 } & \multirow{2}{*}{ قيمة ت } & \multicolumn{2}{|c|}{ الانحراف المعياري } & \multicolumn{2}{|c|}{ المتوسط الحسابي } & \multirow{2}{*}{ معايير التقويه } & \multirow{2}{*}{ r } \\
\hline & & بعلدى & قبلى ق ق ق & بعدى | بعى & 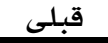 & & \\
\hline 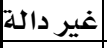 & 1,71 . & $\cdot$, ovir & $\cdot, V \vee 71$ & r,ITrr & 1,ヘTTV & تضمن المشغولة للقيم الفنيـة & 1 \\
\hline 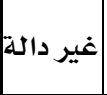 & 1,011 &., 9970 & - VIr. & $r, r \cdots$ & $1,9 \ldots$ & 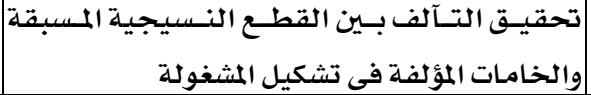 & $r$ \\
\hline 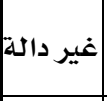 &., 017 & $\cdot, \wedge \wedge \varepsilon \vee$ & $\cdot, V \leqslant Y \wedge$ & $1,9 \cdots$ & $\uparrow, \cdots$ & 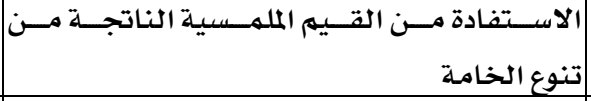 & $r$ \\
\hline 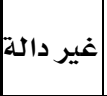 & $\cdot, \varepsilon \cdot r$ & $\cdot, V \mu \cdot r$ & $\cdot, V \backslash \leqslant \varepsilon$ & 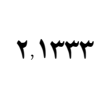 & $r, Y \cdots$ & 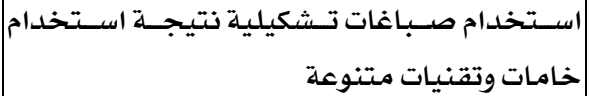 & $\varepsilon$ \\
\hline 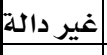 & $\cdot, 10 \varepsilon$ & $\cdot, \vee \neg \Sigma q$ & $\cdot, \Lambda \mathrm{YVV}$ & 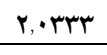 & $r, \cdot 7 T V$ & الدقة والمهارة فى إخراج المشغولة الفنية & 0 \\
\hline 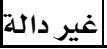 & $\cdot, 7 \leqslant 1$ & 1,0779 & I,VYrV & $1 \cdot, 2 \ldots$ & $1 \cdot 177 \mathrm{~V}$ & الدرجة الكلية (الثراء) & 7 \\
\hline
\end{tabular}

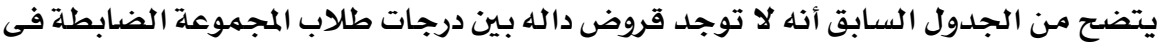

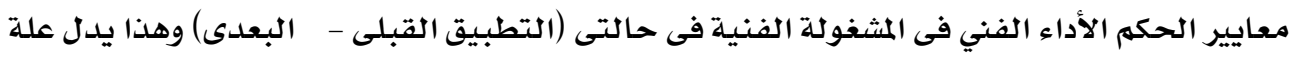

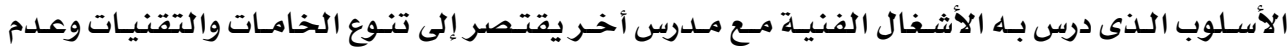

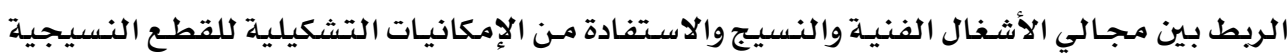

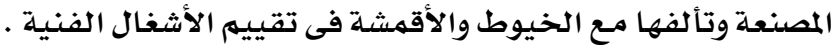

$$
\begin{aligned}
& \text { وبذلك لم يصـح هذا القرض . } \\
& \text { نتائج الفرض الثالث ومناقشته } \\
& \text { ينص الفرض الثالث على : }
\end{aligned}
$$

" توجد فروق ذات دلاله إحصائية بين متوسط درجات أفراد المجموعة التجريبية فى القياس القبلى

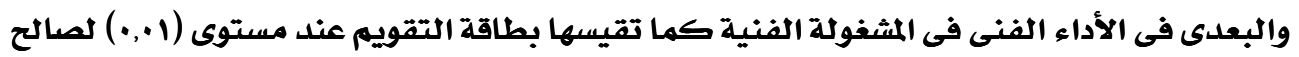

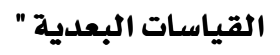

وللتأكـد مـن صسحة هـذا الفـرض قامـت الباحثة بحسساب نسبة (ت) للمتوسطين المرتبطين

وجاءت النتائج كما يلى: ولئًاصك مين 


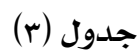

دلالة الفروق بين متوسطات القياسات القبلية والبعدية للأداء الفنى للمشغولة الفنية

ل الدى المجموعة التجريبية

\begin{tabular}{|c|c|c|c|c|c|c|c|}
\hline \multirow{2}{*}{ 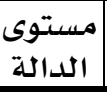 } & \multirow{2}{*}{ 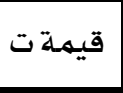 } & \multicolumn{2}{|c|}{ الانحراف المعيارى } & \multicolumn{2}{|c|}{ المتتوسط الحسـابى } & \multirow{2}{*}{ معايير التقويم } & \multirow{2}{*}{ s } \\
\hline & & بعدى & قبلـي & بعدى & قبلي & & \\
\hline دالة & $-74, Y Y A$ & $\cdot$, VTAV & $\cdot, \vee \vee \neg Q$ & 9, r)TV & 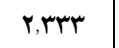 & تضمن المشغولة للقيم الفنية & 1 \\
\hline دالة - مالة & -VI,7rq & $\cdot, 7 \wedge 1 \varepsilon$ & $\cdot, \vee \vee \leqslant q$ & $9, \Sigma 77 V$ & 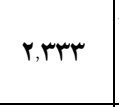 & والخـامـات المؤلفة في تشكيلف القطع النسجية المسبقة & $r$ \\
\hline دالة & $-7 \cdot, \cdot 10$ & $\cdot, 74 \wedge V$ & $\cdot, V I r$ & 9, r)TV & $1,9 \ldots$ & تلنوع الخامـفـادة مـن القيهم الملمسـيـة الناتجـة مـن & $r$ \\
\hline دالة - ل الة & $-V \curlyvee, \Lambda 1 \xi$ & $\cdot .0071$ & $\cdot, \backslash \backslash \wedge \varepsilon$ & 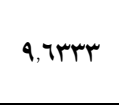 & 1,9778 & 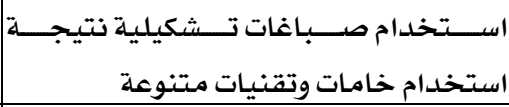 & $\varepsilon$ \\
\hline 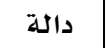 & $-\varepsilon r, \xi \wedge$. & $\cdot, 7 Y 10$ & $\cdot, \mathrm{VAV} \wedge$ & $৭, \varepsilon \cdots$ & $r, \cdots$ & الدقة والمهارة فى إخراج المثغولة الفنية & 0 \\
\hline 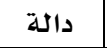 & $-1 \cdot \varepsilon, V 7$ & $1, \varepsilon r \cdot \wedge$ & $1,9 \leqslant 97$ & \&V,rmr & 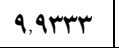 & الدرجة الكلية (الثراء) & 7 \\
\hline
\end{tabular}

يتضح مـن جـدول (r) وجود فروق دالـة إحصائياً عند مستوى (1 .. •) بـين القياسـات القبلية

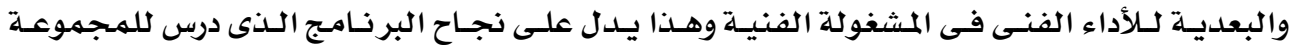

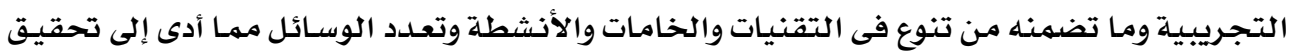
درجة الثراء الكلى للمشغولة الفنية مما يؤكد صحسة الفيات الفرض. نتائج الفرض الرابع ومناقشته

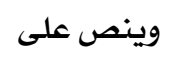

"توجد فروق ذات دلالة إحصائية بين متوسطى درجات أفراد المجموعتين التجريبيتين والضابطة فى الأئ

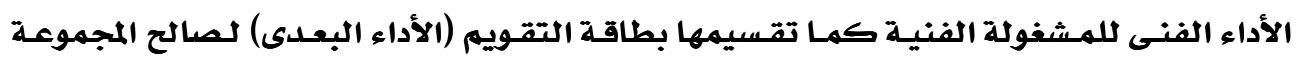
التجريبية عند مستوى (1. (-.)

وللتحقق من صحة هـذا الفرض والتحقق مـن مـدى قبوله أو رفضه تم التأكد مـن درجـات

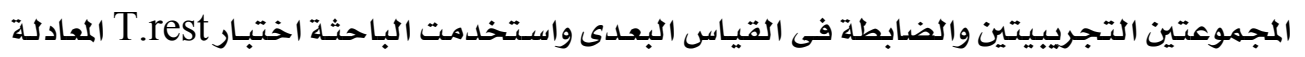

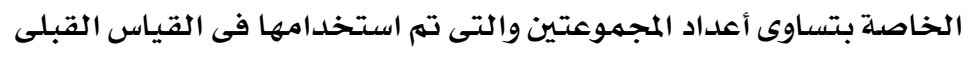

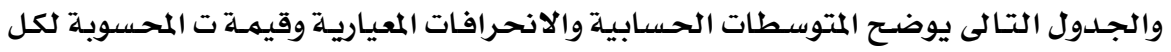

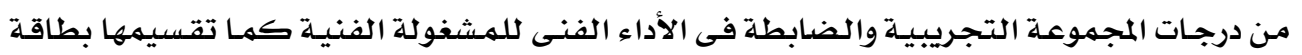

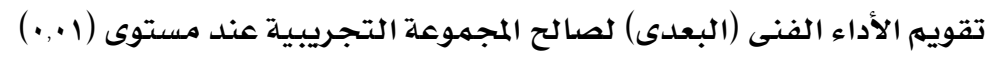




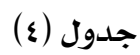

المتوسطات الحسابية والانحرافات المعيارية وقيمة (ت) لطلاب المجموعتين الضابطة والتجريبية

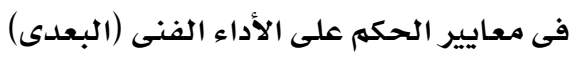

\begin{tabular}{|c|c|c|c|c|c|c|c|}
\hline \multirow{2}{*}{ 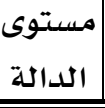 } & \multirow{2}{*}{ 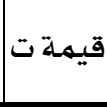 } & \multicolumn{2}{|c|}{ الانحراف المعياريى } & \multicolumn{2}{|c|}{ المتوسط الحسـابى } & \multirow{2}{*}{ معايير التقويه } & \\
\hline & & ضابطة & تجريبية & ضابطة & تجريبية & & \\
\hline دالة - ل الة & $\left\{0, \cdot 0_{0}\right.$ & $\cdot$. OVIr & - STAV & 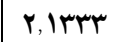 & Q,rרד & تضمن المشغولة للقيم الفنية & 1 \\
\hline دالة & rY,971 & $\cdot, 9970$ & $\cdot, 7 \wedge 1 \varepsilon$ & r,r. . & $9, \varepsilon 77 \vee$ & 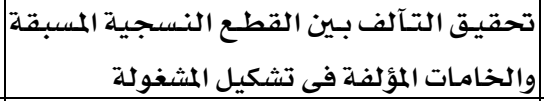 & r \\
\hline دالة & $\mathrm{r}, \wedge \mathrm{VV}$ & $\cdot, \wedge \wedge \leqslant \vee$ & $\cdot, T 7 \wedge V$ & $1,9 \ldots$ & 9, rTTV & | الاسـتفـادة مـن القـيم الملمـسـية الناتجــة مـن & $r$ \\
\hline 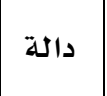 & $\{\varepsilon, \vee \circ\}$ & $\cdot \boldsymbol{V}$ & $\cdot, 0071$ & 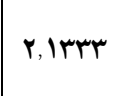 & צוrד 9 & 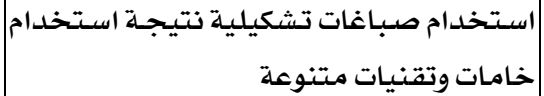 & $\varepsilon$ \\
\hline دالة & $\varepsilon \cdot, 9 \leqslant 1$ & $\cdot, \vee \vee \leqslant 9$ & $\cdot, 7 Y 10$ & 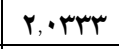 & $9, \varepsilon \cdots$ & الدقة والمهارة فى إخراج المشغولة الفنية & 0 \\
\hline 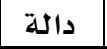 & $90, \cdot \sqrt{9}$ & 1,0779 & $1, \varepsilon r \cdot \Lambda$ & $7 \cdot, \ldots$ & EV,Yrm & الدرجة الكلية (الثراء) & 7 \\
\hline
\end{tabular}

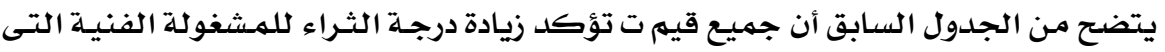

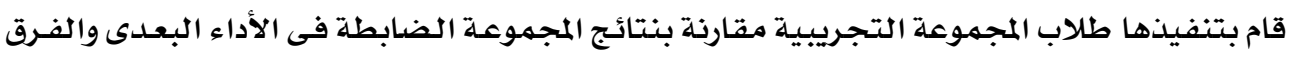

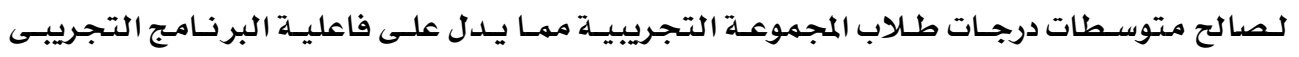

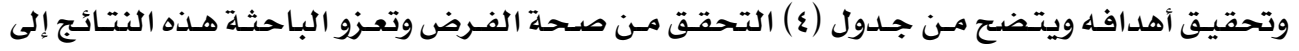

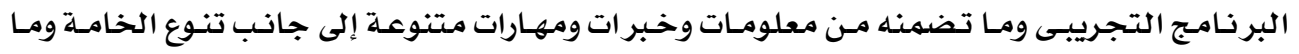
تتضهنـه مـن إمكانيات تشكيلية ساعد على تأكيد درجـة الثراء الكلى للهـشغولة الفنيـة مقارنـة بنتائج المجموعة الضابطة.

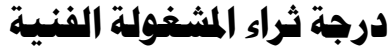

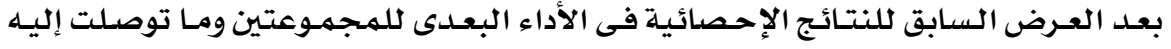

الدراسـة من نتائج ودرجات عالية لصالح المجموعة التجريبية الاحتية.

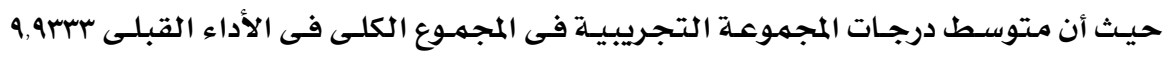

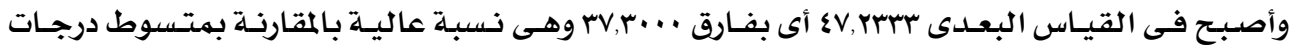

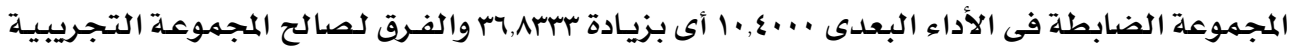

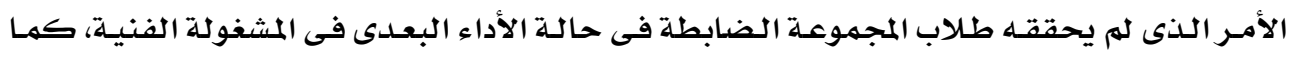

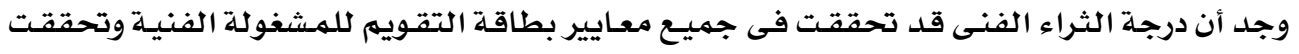

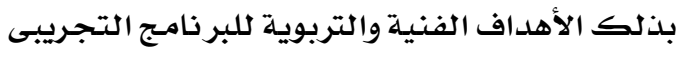


توصى الدراسـة بـالبـحث عن كـل مـا هـو جديــ مـن خـامـات ومحاولـة الإفـادة مـن إمكانياتها التشكيلية لإثراء المشغولات الفنيـة. • ريط مجال الأشغال الفنية بهجالات التربية الفنية الأخرى.

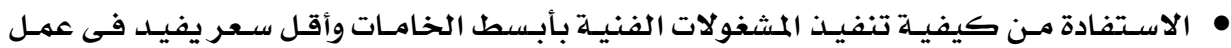
مشروعات صغيرة تفيد خريجى التربية النوعية.

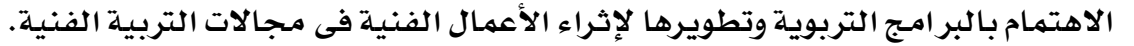

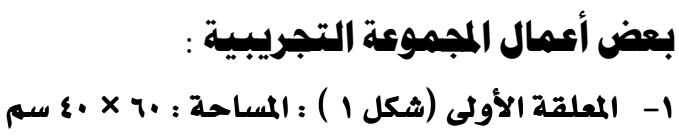

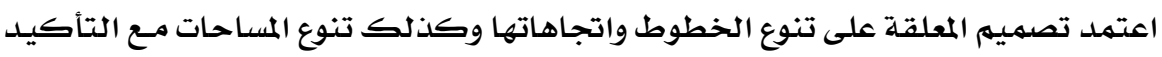

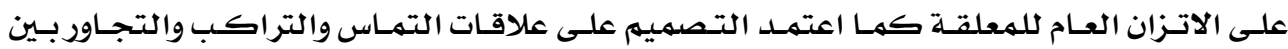

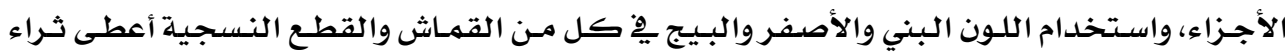
وتوافق لوني يْ المعلقة.

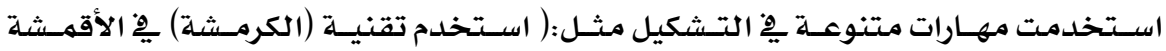

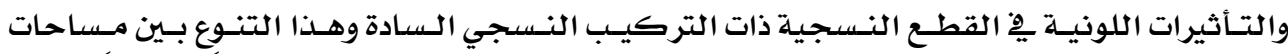

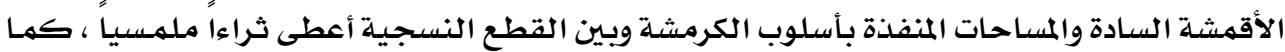
استخدمت خيوط المكرمية لتحديد بعض الأشكال والريط بين أجزاء التصميهم. r- المعلقة الثانية (شكل r) : المساحة : •7 × • •ع سم

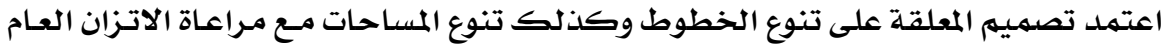
للمعلقة معتمدة على علاقات التماس والتجاور والتراكب بين الأجزاء.

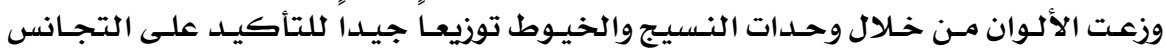

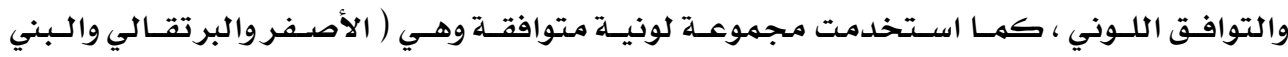
ودرجاته).

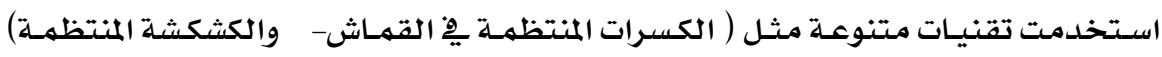
واستخدمت تقنيات (لف الخيوط فوق المساحة والتجاوروالترصيص وبرم الخيوط). تم توزيـع التقنيات والأسـاليب التشكيلية وترديدها لتحقيق التناغم اللوني والإيقـاع الشكلي الذي أثرى المعلقة من الناحية الجمالية.

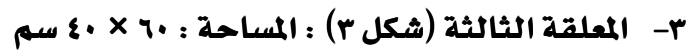
اعتمد التصميم على التنوع ِِِ المساحات الهندسية ، واستخدمت مجموعة لونيـة متوافقـة

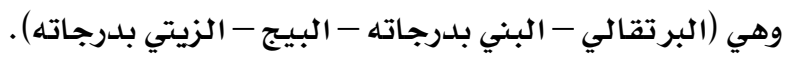


استخدمت مهارات متنوعة هِّ التشكيل مثل:(استخدام أكثر مـن نوع مـن القماش (ستان -

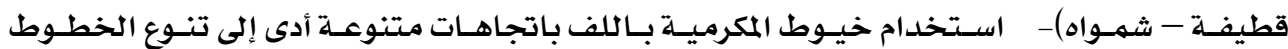

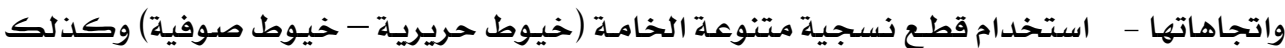

تنوع هٌِ التراكيب النسجية المستخدمة).

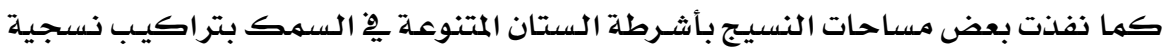
متنوعة ، مما أدى إلى تجانس بين أشرطة الستان المستخدمة والقماش الستان وكذلك التهان التجانس بين القماش القطيفة والشمواه.

وأدى التوزيع الجيد للتقنيات التشكيلية وترديدها إلى أحداث التنـاغم والإيقاع ، كهـا أدى الدي

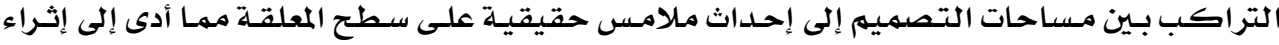
المعلقة من الناحية الجمالية.

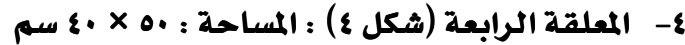
اعتمـد التصميم على التزاوج بـين الخط الهندسي الحساد وبـين الخطوط اللينـة نتـج عنـه

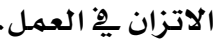

استخدمت مجموعة لونية متوافقة وهي (البرتقالي - البني بدرجاته - الأصفر) والتبـادل

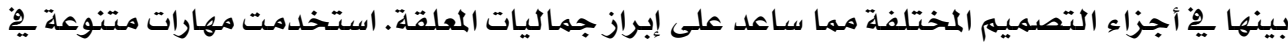

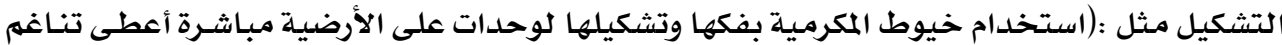
إيقاعي نتيجة مسار الخيوط وحقق نوعا من الترابط والاتزان.

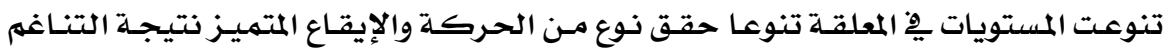

الحر بين الأجزاء المكونة للتصميه والقطع النسجية.

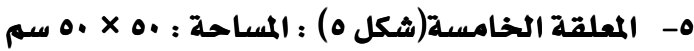

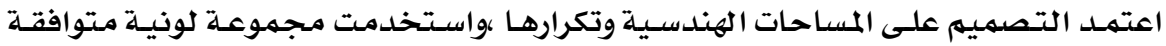

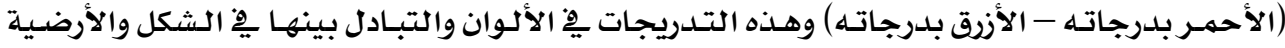

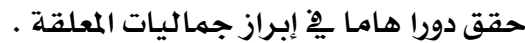

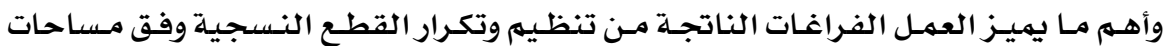

التصميهم مما أحدث نوعا من العلاقة الجمالية المتبادلة بين الشكل والأرضية.

استخدمت تقنيات متنوعة أدت إلى الثراء الشكلي والملمسي يُ القطع النسجية والخيوط ـ.

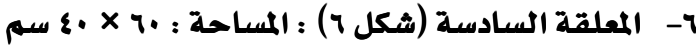

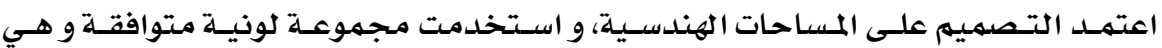

(الأحمر - البرتقالي - الأصفر - الموف بدرجات منه).

واستخدمت مهارات متنوعة يو التشكيل مثل :(توزيع القطع النسجية توزيعا حرا متناسقاً

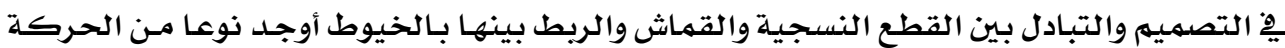




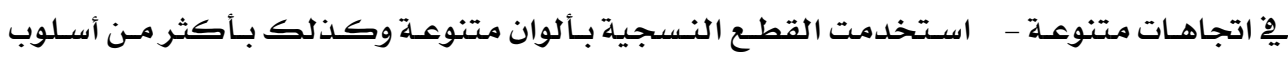
للتركيب النسجي مما أدى إلى ثراء المعلقة).

استخدام خيوط المكرمية بشكل متعحامد متلاقي يِّ الأرضـيـة أدى إلى إيجـاد نوع مـن الترابط ليط

بين أجزاء التصميه.

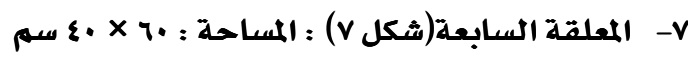

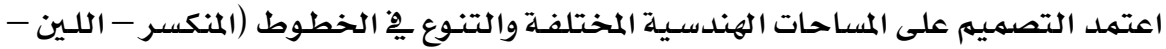

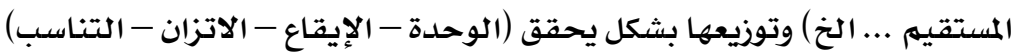

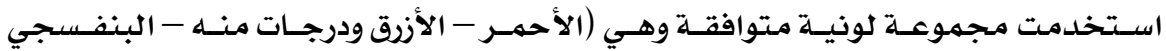

ودرجات منسه - البرتقالي) .

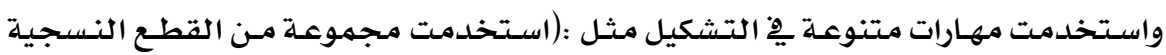

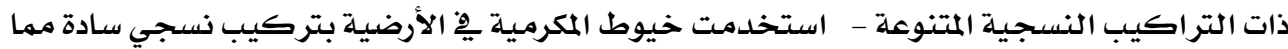

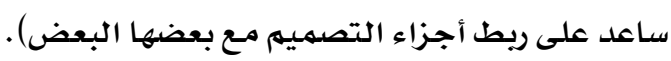

وتم التبادل يِّ الألوان بين الأرضية والتصميهم وبـين مسـاحات التصميهم المختلفـة مهـا سـاعد

على إبراز جماليات المعلقة.

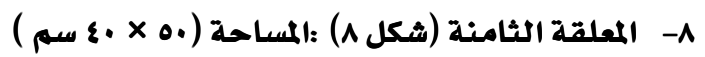

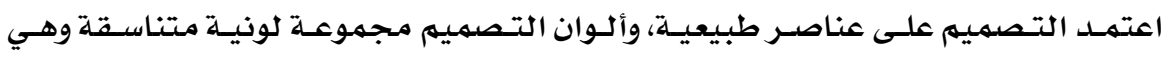

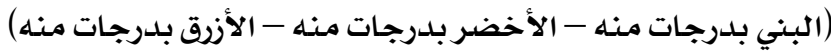

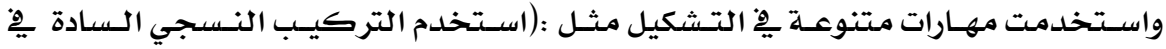

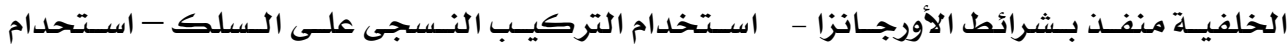

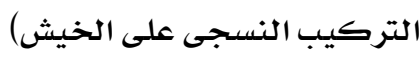

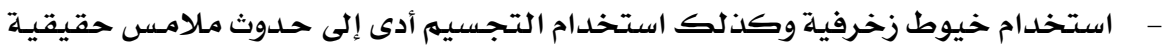

على سطح المعلقة ، وهذا التتـوع فى أسـاليب التشكيل وفى الخـامـات أدى إلى ثراء المعلقـة مـن النـاحيـة إلى حلى

الجمالية

9- المعلقة التاسعة(شكل 9) : المساحة ( •ع × .0 سم)

التصميهم هندسي يعتمد على الخط (المنحني - المنكسر- المستقيم)

ألـوان التصميهم مجموعـة لونيـة متناسـقة وهي (البني - الأخضر - البرتقـالي - الأصفر)

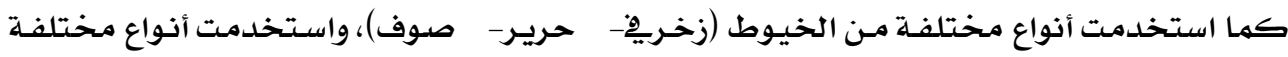
من القماث (قطن - شمواه). وزعت القطع النسيجية يِّ أجزاء متتوعة ِِِ التصميم توزيعا جيداً. 
استخدمت مهارات متتوعة للتشكيل مثل: لف الخيوط ِِّ بعض الأجـزاء لفـا منتظمها وِيِ أجـزاء أخـرى غـير منـتظم، كهـا تم تحديـد بعض الأجـزاء بخيـوط المكرميـة مهـا ســاعد على تحقيق

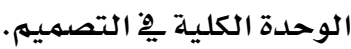

•- المعلقة العاشرة (ثكل •1) : المساحة ( •ع × .0 سم)

التصميهم هندسي ولعب الخط فيه دورا هاما وألوان التصميهم مجموعة لونية متناسقة وهي

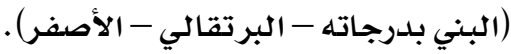

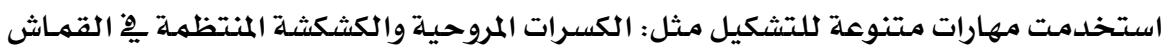

، كما استخدمت تقنية لف الخيط بطريقة شبكية متداخلة مما أدى إلى جمال المساحة نتيجـة تعـدد

اتجاهات لف الخيوط.

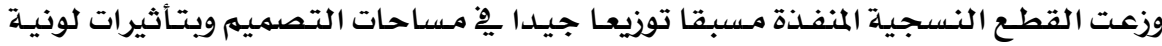

متمشية مـع ألوان التصميهم مما أدى إلى التجانس الكلي للتصميهم.

11- المعلقة الحادية عشر(ثكل 11) : المساحة ( .0 × • ع سم )

اعتمد التصميهم على الفن الشعبي ورموزه ، وألوان التصميهم مجموعة لونيـة متناسقة وهي

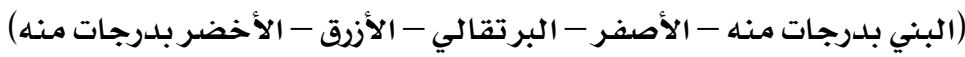

استخدمت مهارات متنوعة فِ التشكيل مثل:( القطع النسجية بخيوط زخرفيـة - التجسيهم

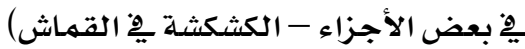

وهذا التنوع أدى إلى ثراء المعلقة من الناحية الجمالية كما تم إضـافة بعض الإكسسوارات

مثل الخرز لتأكيد جماليات التصميه.

r ا- المعلقة الثانية عشر (شكل rا1) : المساحة ( •7 X •ع سم)

اعتمــ التصـميهم على شـكل هندسـي وهـو المربـع ، حيـث تم تقـسيم الـشكل إلى مربعـات ذات

مستويات مختلفة مما سـاعد على حدوث ملامس حقيقية على سطح المعلقة.

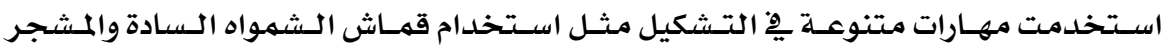

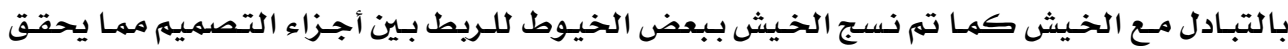

الوحلدة الكلية يِّ التصميه.

واستخدمت القطع النسجية ِِِ التصميهم بخيوط زخرفية ، وهذا التنوع ِِِ التشكيل أدى إلى

ثراء المعلقة من الناحية الجمالية. 


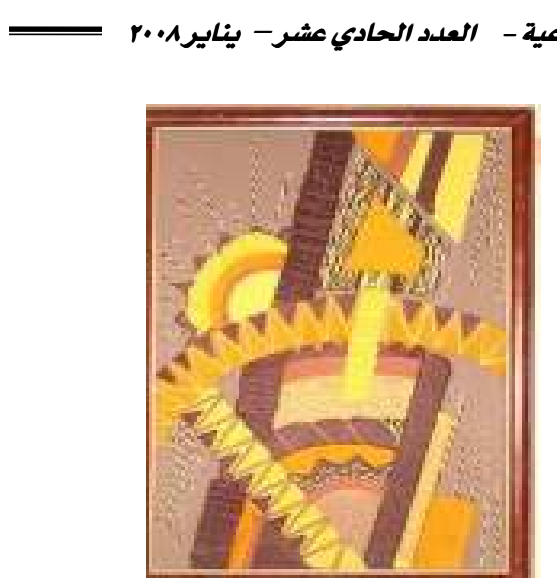

شكل (r)

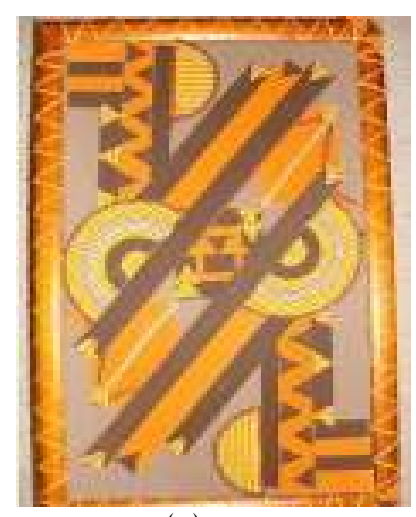

شكل (§)

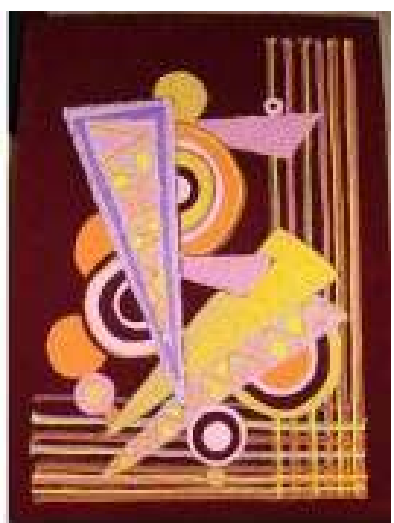

شكل (؟)

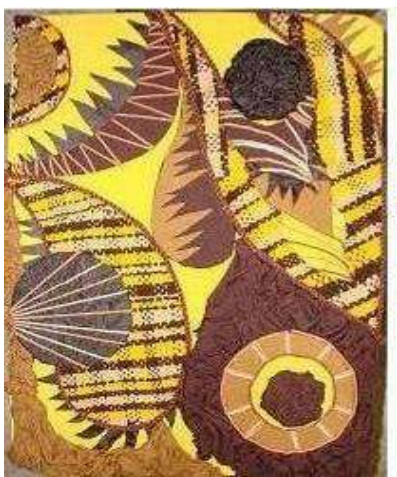

شكل (1)

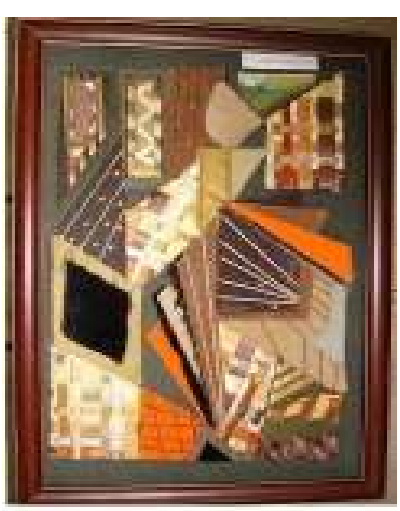

شكل (r)

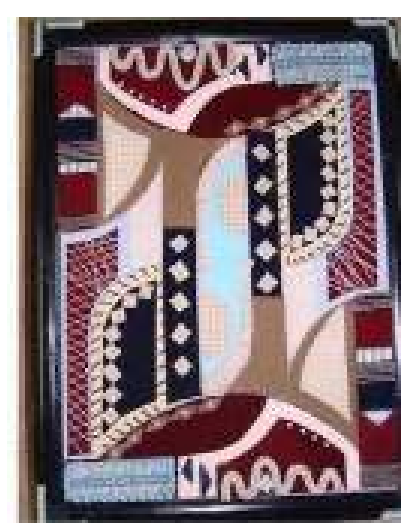

شكل (0) 


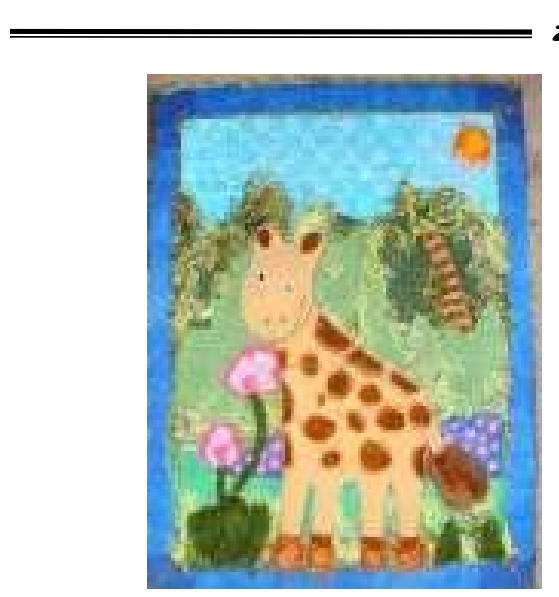

شكل (^)

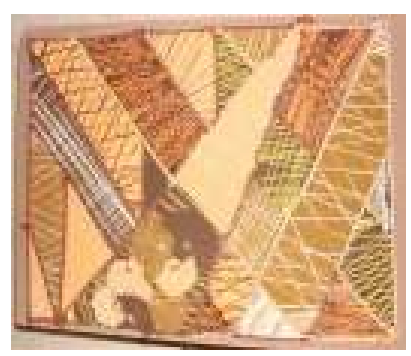

شكل (.)

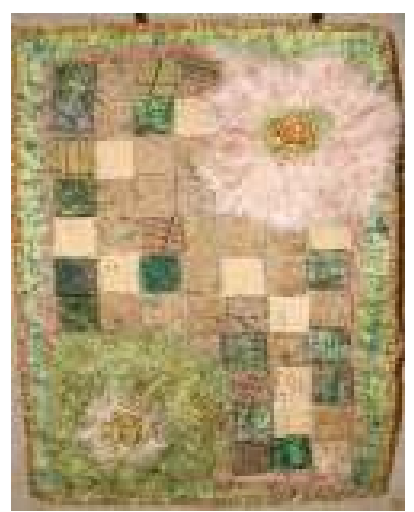

شكل (r)

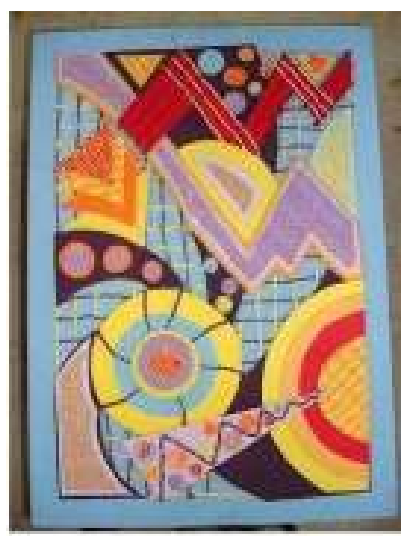

شكل (v)

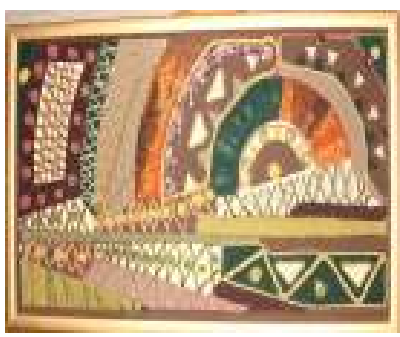

شكل (a)

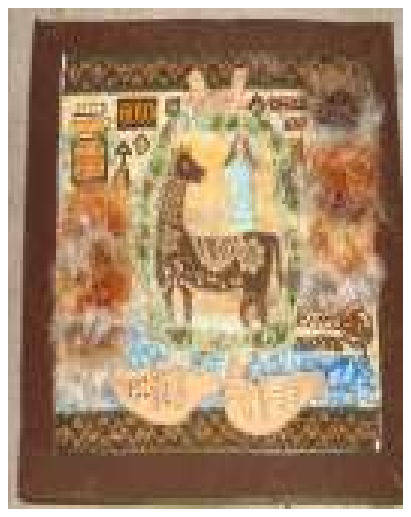

شكل (11) 
1 ـ أحمد حافظ رشدان - فتح الباب عبد الحليه : التصميم - دار المعارف - القاهرة - • 19V.

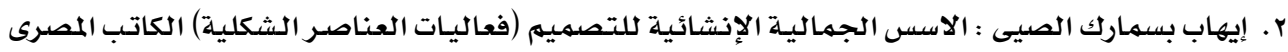

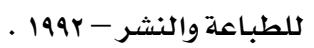

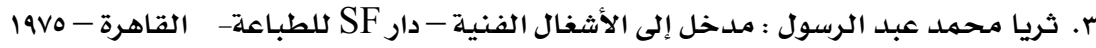

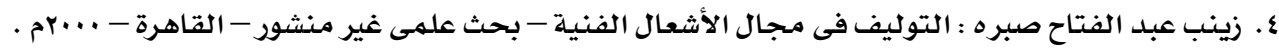

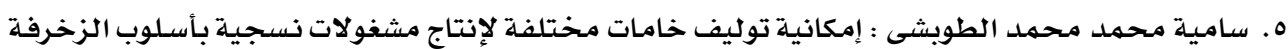

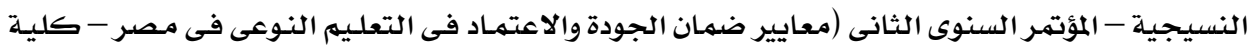

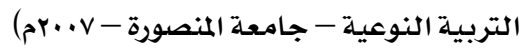

1. سحر الهادى مصطفى : الإمكانيات التشكيلية لبقايا الأقمشة والإفادة منها فى إنتاج مشغولات نسيجية رسالة ماجستير غير منشورة - كلية التربية النوعية - جامعة حلوان - 1997 ام.

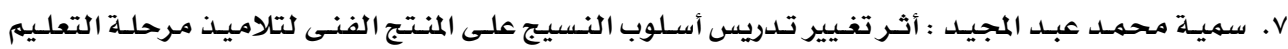

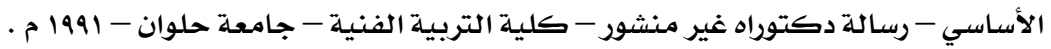

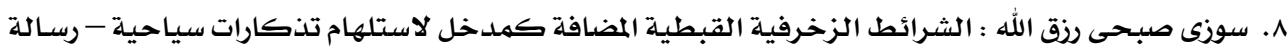

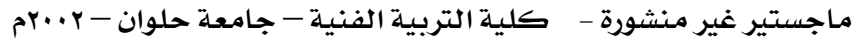

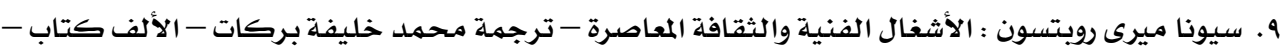

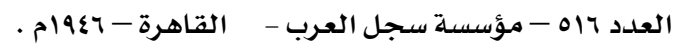

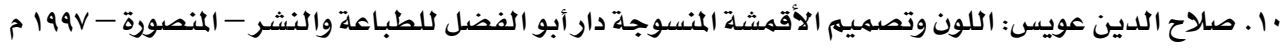
Iا . عبد الرافع كامل : تكنولوجيا النسيج (لتحليل المنسوجات) طا الجزءء الثالث - دار المعـارف - القـاهرة -

r ا. عبد الفتاح رياض : التكوين فى الفنون التشكيلية - دار النهضة العربية- طب - 19Vץ م

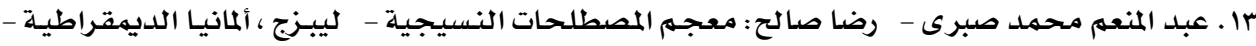
. 19v0

ـا ـ عواطف فتح الله المرصفى: أثر توليف الخامـات فى التعبير الفنى عنـل تلاميـذ المرحلـة الإعداديـة- رسـالة

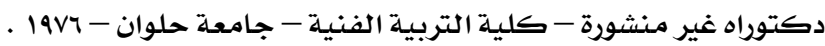

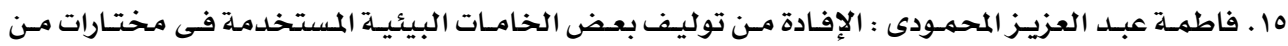
المثغولات الشعبية لعمل مكمملات مبتكرة للزينـة - رسـالة دكتوراه غير منشورة - كليـة التربيـة الفنيـة -

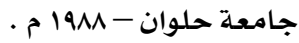

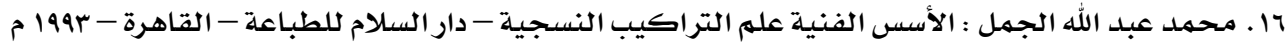
IV . محمد هانى فخرى : التوليف بالخامات النسيجية كمصدر لإثراء التشكيل الفنى - رسالة ماجستير غير الإلير

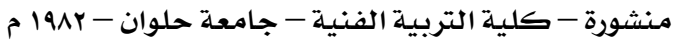
11 ـ محمود البسيونى : نحت الأطفال - دار المعارف - القاهرة - 1979 م 
19 ـ ـ محمود النبوى الشال وآخرون : مناهج وطرق تدريس التربية الفنية - دار العالم العربى - القاهرة - 19Ar

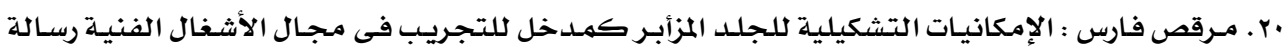

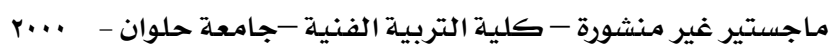

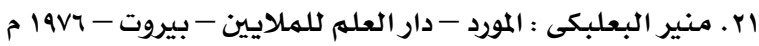

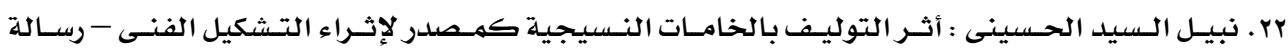
ماجستير - غير منشورة - كلية التربية الفنية - جامعة حلوان - 1919 م م .

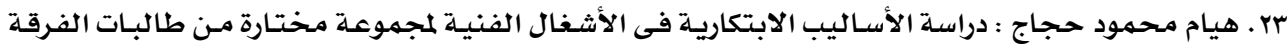

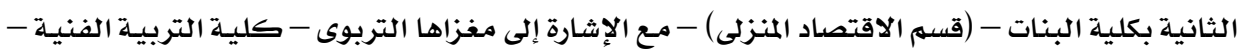

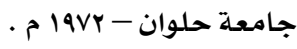
ثانياً : المراجع الأجنبية

24. Fowlen , HW. A, Fowler . FG . Theconics Oxford . Dictionary Oxford . Univeristy Ptoss, 1946.

25. Jan Janciro and Jacklemorlassem : Fiberants Design Book Five - U . S . A . larks . 1996.

26. Runes, Dayabest : Encyclopedia of The Art, New york, philosophical , 1996.

المهام البحثية التى قامت بها الباحثة مـاجدة ثوقى بطرس مدرس المناهج وطرق التدريس ما يلى:

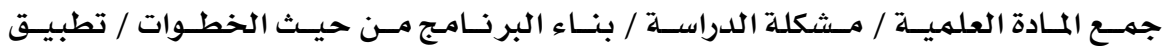

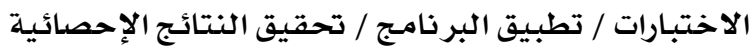
المهام البحثية التى قامت بها الباحثة منال فوزى بهنسى مدرس الأشغال الفنية المشاركة فى تطبيق البرنامج / تفسير النتائج ومناقشتها المهام البحثية التي قامت بها الباحثة مها على الشيمى مدرس النسيج

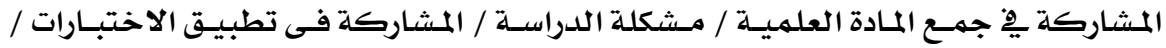

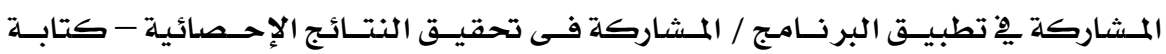
وتنظيم المراجـع. 